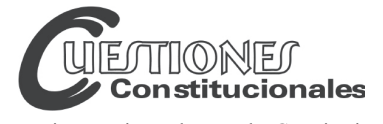

Revista Mexicana de Derecho Constitucional

Núm. 27, julio-diciembre 2012

\title{
EL PRIMER CONGRESO CONSTITUYENTE MEXICANO
}

\author{
THE FIRST MEXICAN CONSTITUYENT CONGRESS
}

\section{José Luis SOBERANES FERNÁNDEZ*}

\begin{abstract}
RESUMEN: En el presente trabajo se describe uno de los momentos más difíciles de la historia constitucional de México, por no decir el más difícil, que va desde la Consumación de la Independencia Nacional del 27 de septiembre de 1821 al 30 de noviembre de 1823 en que clausuró sus sesiones el Primer Congreso Constituyente. Fue cuando se erigió el Imperio de Iturbide y su ocaso, en consecuencia triunfó la república y se planteó seriamente el federalismo. Se eligió ese primer constituyente, se clausuró, apareció la Junta Nacional Instituyente, triunfó la Revolución de Casa Mata, se cerró la mencionada Junta y se reabrió el Congreso, para convocar el Segundo Constituyente y cesar en definitiva.
\end{abstract}

Palabras clave: Casa Mata, Congreso Constituyente, federalismo, Imperio, Junta Nacional Instituyente, Junta Provisional Gubernativa, Reglamento, Provisional Político del Imperio, República.
ABSTRACT: This work describes one of the more, if not the most, difficult moments in Mexico's constitutional history of Mexico, a period that goes from the Consummation of the National Independence on September 27th, 1821 to November 30th, 1823 when the sitting of the first Constituent Congress was concluded. This happened with the establishment and fall of Iturbide's Empire and, consequently, the republic became triumphant and federalism was seriously considered. That first Constituent Congress was established and concluded, the National Founding Body appeared, the Casa Mata Revolution triumphed, the aforementioned Body was closed and Congress was re-opened in order to call for a second constituent and to cease in a definitive manner.

Descriptors: Casa Mata, Constituent Congress, Federalism, Empire, National Founding Body, Provisional Gubernative Body, Provisional Political Rules of the Empire, Republic.

* Investigador en el Instituto de Investigaciones Jurídicas de la Universidad Nacional Autónoma de México. 


\section{PLANTEAMIENTO}

De conformidad con lo dispuesto en los artículos 5 a 7 del Plan de Iguala del 24 de febrero de 1824, así como 6 a 12 de los Tratados de Córdoba del 24 de agosto del mismo año, desde el 22 de septiembre siguiente, hasta el 25 de febrero de 1822, nuestro país estuvo gobernado por una Junta Provisional Gubernativa, que además tomó el título de Soberana. O sea, fue la primera autoridad política que tuvo México a partir de su Independencia.

Huelga decir la importancia que tuvo dicho órgano de gobierno en los inicios del constitucionalismo del México Independiente, hasta el establecimiento de nuestro Primer Congreso Constituyente; por tal motivo, comenzaremos el presente trabajo ocupándonos, brevemente, como es lógico, de esta Junta, en donde encontraremos los cimientos del México contemporáneo.

En efecto, el artículo 6o. del Plan de Iguala, antes citado, disponía que dicha Junta:

se compondrá de los vocales ya propuestos al señor virrey”, y en el artículo 6o. de los Tratados de Córdoba, sólo se señalaba "se nombrará inmediatamente ... una Junta compuesta de los... primeros hombres del Imperio por sus virtudes, por sus destinos, por sus fortunas, representación y concepto, de aquellos que están designados por la opinión general, cuyo número sea bastante considerable para que la reunión de luces asegure el acierto en sus determinaciones.

Al ser ambos documentos los únicos textos que regirían los primeros pasos de la nación neonata, teniendo a la Constitución de Cádiz y legislación reglamentaria como normas supletorias, quedaba claro que don Agustín de Iturbide se reservó el derecho de determinar los nombres y 
número de los vocales integrantes de la mencionada Junta, como de hecho así sucedió. ${ }^{1}$ Sobre el particular, Iturbide manifestó: ${ }^{2}$

Fue elegida por mí, pero no a mi arbitrio, pues quise sobre todo en su totalidad llamar a aquellos hombres de todos los partidos que disfrutaban cada uno en el suyo el mejor concepto, único medio en estos casos extraordinarios de consultar la voluntad del pueblo.

La Junta tendría las facultades que en España se habían otorgado a las Cortes, o sea de poder legislativo, ya que el ejecutivo lo ejercería una Regencia (igual que en España, en la ausencia del rey), cuyos integrantes serían nombrados por aquélla (recordemos que en ambos documentos citados se preveía que México sería una monarquía). El papel más importante de la Soberana Junta Provisional Gubernativa iba a ser, obviamente, convocar al Congreso Constituyente, dando las reglas para ello.

\section{II.Y LA JUNTA COMIENZA A TRABAJAR}

En la Villa de Tacubaya, el 22 de septiembre de 1821, cinco días antes de la solemne entrada del Ejército Trigarante en la ciudad capital, tuvo su primera sesión preparatoria la Junta Provisional Gubernativa a la que se referían los artículos quinto del Plan de Iguala, sexto y séptimo de los Tratados de Córdoba, antes citados, con el único fin de subdividir el trabajo propio en comisiones, además de designar a los integrantes de las mismas.

La segunda sesión preparatoria tuvo lugar el día 25 del mismo mes, en la misma localidad, con el objeto de tomar los primeros acuerdos, con base en

1 Ya desde el 24 de febrero de 1821, Iturbide había hecho un primer proyecto de lista de integrantes de la Junta Gubernativa, misma que envió al virrey, Conde del Venadito, ahí encontramos al propio Conde del Venadito como presidente, al regente de la Audiencia, Miguel de Bataller, como vicepresidente, además de Miguel Guridi y Alcocer, el Conde de la Cortina (Vicente Gómez de la Cortina y Salcedo), Juan Bautista Lobo, Matías de Monteagudo, Isidro Yáñez, José María Fagoaga, Juan José Espinosa de los Monteros, Juan Francisco Azcárate, Rafael Suárez Pereda, como miembros titulares (de ellos, salvo el Conde de la Cortina, posteriormente fueron nombrados efectivamente) y Francisco Sánchez de Tagle, Ramón Oses, Juan José Pastor Morales e Ignacio Aguirrebengoa, como suplentes.

2 Cfr. "Memoria del ilustre príncipe emperador de México hechas en su destierro", en Gutiérrez Casillas, S. J., José (ed.), Papeles de don Agustín de Iturbide. Documentos hallados recientemente, México, Tradición, 1977, p. 225. 
los dictámenes presentados por las diversas comisiones antes mencionadas. Los más importantes acuerdos fueron los relativos al carácter y atribuciones de la propia Junta y de la Regencia, entre los que destacan:

1. Que la Junta concluiría sus funciones cuando estuvieran reunidas las Cortes; es decir, el Congreso Constituyente.

2. Tendría el título de Soberana y el tratamiento de "majestad" y se integraría con cinco comisiones, de acuerdo con la división tradicional de las secretarías del despacho: relaciones interiores y exteriores, justicia y eclesiástico, hacienda y guerra.

3. Que la Junta tendría las mismas facultades que la Constitución de Cádiz atribuía a las Cortes españolas, en lo que no se opusieran a los Tratados de Córdoba; entendiéndose ello con carácter provisional, hasta que el Congreso Nacional resolviera lo definitivo.

4. La Regencia tendría las mismas facultades que tuvo la Regencia española. Se le asignó el tratamiento de "alteza".

5. Se reconocería la deuda nacional.

6. Se creaba una orden militar, denominándose Imperial del Águila Mexicana.

Vino la entrada triunfal del Ejército Trigarante en la Ciudad de México el 27 de septiembre, cumpleaños de Iturbide, con lo cual se significó la Consumación de la Independencia. Al día siguiente se volvió a reunir la Soberana Junta $^{3}$ a las ocho y media de la mañana, en el antiguo Palacio Virreinal, ahora denominado "Nacional", en una sesión protocolaria; de ahí pasaron

\footnotetext{
La Junta estuvo finalmente integrada por: Antonio Joaquín Pérez, Obispo de Puebla, Juan de O’Donojú, jefe político superior — virrey — nombrado por España, Manuel de la Bárcena, Arcediano de la Catedral de Valladolid de Michoacán, Matías Monteagudo, José Isidro Yáñez, oidor, Juan Francisco Azcárate, Juan José Espinosa de los Monteros, José María Fagoaga, Miguel Guridi y Alcocer, Miguel Cervantes y Velasco, Manuel de Heras Soto, Juan Bautista Lobo, Francisco Manuel Sánchez de Tagle, Antonio Gama, José Manuel Sartorio, Manuel Velásquez de León, Manuel Montes Argüelles, Manuel Sota Riva, Mariano Zardaneta, Ignacio García Illueca, José María Bustamante, José María Cervantes y Padilla, José Manuel Velázquez de la Cadena, Juan Horbegoso, Nicolás Campero, Pedro José Romero de Terreros, José María Echevers, Manuel Martínez Mansilla, Juan Bautista Raz y Guzmán, José María Jáuregui, Anastasio Bustamante e Isidro Ignacio Icaza. También estaban designados, aunque no asistieron a esa reunión del día 28, los señores: José Mariano de Almanza, José Domingo Rus, José María Cervantes y Velasco, Rafael Suárez Pereda y Miguel Sánchez Enciso. Funcionaron como secretarios Espinosa de los Monteros y Suárez Pereda.
} 
a la Catedral Metropolitana a rendir el juramento de estilo, y en el propio recinto eclesiástico se eligió a don Agustín Iturbide como presidente de la Suprema Junta, se cantó Te Deum y se dijo una misa.

Ese mismo día, a las siete y media de la noche, igualmente en Palacio Nacional, se volvió a reunir la Soberana Junta Gubernativa, para aprobar y suscribir el Acta de Independencia del Imperio 4 y a elegir a los miembros del Consejo de Regencia, que aunque se había dispuesto en el artículo 11 de los Tratados de Córdoba, fuera de tres individuos, se vio más conveniente integrarla de 5 miembros, así salieron electos: Iturbide, O’Donojú, Manuel de la Bárcena, José Isidro Yáñez y Manuel Velásquez de León. Habiéndose nombrado Iturbide para la Regencia, se eligió nuevo presidente de la Junta, habiendo recaído en el obispo de Puebla, Antonio Joaquín Pérez; igualmente se le dio título de generalísimo y almirante a Iturbide. Para evitar cuestiones protocolarias, tan en boga en ese entonces, se resolvió que en las reuniones de la Junta, estando presente don Agustín, se le daría preeminencia sobre el presidente de la misma Junta.

Nos dice Lucas Alamán ${ }^{5}$ que aquí fue donde tuvieron su origen los partidos liberal y conservador en México, encabezando la primera tendencia don José María Fagoaga, ${ }^{6}$ junto con Francisco Manuel Sánchez de Tagle y Manuel de Heras Soto, junto con la mayoría de los abogados que integraban la Junta; mientras que en la segunda tendencia fue encabezada por don Miguel Guridi y Alcocer.

Así se siguieron reuniendo prácticamente todos los días. Indiscutiblemente el asunto más importante era la expedición de la convocatoria al constituyente, cuya discusión se inició hasta el 23 de octubre de 1821, cuando la "Comisión sobre Convocatoria de Córtes" (integrada por Monteagudo,

4 Esta $A$ cta de Independencia lleva la fecha del día siguiente, 28 de septiembre de 1821, no tiene nada especial, aparte de que la Nación Mexicana es "soberana e independiente de la antigua España" y grandes elogios a Iturbide. No deja de llamar la atención el que se empiece a utilizar cierto lenguaje masónico. En fin, estas actas o declaraciones de independencia fueron una costumbre que adoptaron las naciones del Continente Americano a partir de su emancipación colonial, recordemos que lo propio había sido hecho por el Congreso de Chilpancingo el 6 de noviembre de 1813, a instancias de Morelos. Cfr. Torre Villar, Ernesto de la, "El Acta de Independencia”, La Constitución de Apatzingán y los creadores del Estado mexicano, 2a. ed., UNAM, 1978, pp. 47-54.

5 Cfr. Historia de Méjico, 2a. ed., México, Jus, 1969, t. V, pp. 249 y 250.

6 Español de origen, "afecto á la independencia, por cuya causa había sido preso y expatriado... y muy adicto á las reformas introducidas por las Cortes [de España] en materias religiosas" 
Martínez Mansilla, Horbegoso, Maldonado, Velázquez de la Cadena, Sartorio e Icaza) presentó el dictamen respectivo, a lo cual el Pleno acordó fuese el 30 del mismo mes en que se debatiese; cuando se estaba leyendo dicho dictamen, se presentó el secretario de Relaciones Exteriores e Interiores, don José Manuel de Herrera, y pidió se postergara su resolución hasta conocer el documento que sobre el particular presentaría la Regencia, a más tardar el 3 de noviembre; como de hecho se acordó, no sin antes empezar a reflexionar sobre el valor que le deberían dar a la legislación española en esta materia tan importante; cuestión que se suscitó por una propuesta de integrar al constituyente con dos cámaras. Parece ser que tal idea provenía de Iturbide.

En efecto, de conformidad a lo dispuesto en el artículo 12 de los Tratados de Córdoba, como ya hemos visto, se gobernaría interinamente al país conforme a las leyes vigentes inmediatamente antes de la Independencia, particularmente las gaditanas; por lo cual, los integrantes de la Junta se preguntaron si se podían establecer en la convocatoria reglas distintas, e inclusive contrarias a la legislación española.

Finalmente, el 6 de noviembre se recibió el proyecto de convocatoria de la Regencia y se dispuso que fuese el día siguiente cuando se comenzara a discutirlo, como de hecho así sucedió. Se inició con la lectura de dicha propuesta; sin embargo, se consideró que previamente se tenía que resolver lo que el abogado Antonio Gama planteó, concretamente en estos términos ¿tiene esta Soberana Junta facultad para convocar un Congreso distinto en lo substancial de lo que previene la Constitución de la Monarquía Española?, a lo cual la Junta resolvió "esta Soberana Junta no tiene tal facultad"; resuelto eso, el propio Gama planteó ¿podían hacerse variaciones en la parte reglamentaria?, lo cual se resolvió por la afirmativa. Más adelante, el día 8, se modificó el acuerdo, estableciéndose: "había libertad para variar el modo de convocar el Congreso".

En la sesión del 8 de noviembre se leyó un proyecto de convocatoria del doctor José Eustaquio Fernández, aunque se señaló que sólo los vocales de la Junta y de la Regencia tenían el derecho de iniciativa. En eso llegó la petición de la Regencia de concurrir a la discusión respectiva, lo cual fue acordado que podían acudir pero no participar en la discusión propia de la Junta y mucho menos en la votación. Acudió personalmente Iturbide. 
Resulta interesante señalar que en alocución declaró: "convendría tener presente que residiendo la soberanía en el pueblo...".

Como apuntamos antes, se había modificado el criterio anteriormente resuelto y se acordó "que había libertad para variar el modo de convocar al Congreso", por lo cual, se resolvió que el Congreso se dividiría en dos salas y se revisaran mutuamente sus acuerdos (aunque en la práctica no se hizo así), y de esta forma darle gusto, aunque de forma parcial, al generalísimo. A continuación Iturbide presentó su personal propuesta de convocatoria, para lo cual se nombró una comisión ad-hoc, para estudiar dicha propuesta, y se fijó el sábado 10 del mismo mes para avocarse al debate, como de hecho así se hizo, con la presencia de los miembros de la Regencia. Finalmente, se aceptó la propuesta de Iturbide y las observaciones de la Regencia.

¿Qué había de fondo? No era otra cosa que dos propuestas de cómo se debería integrar el Constituyente. Jaime E. Rodríguez O. ${ }^{8}$ nos explica que efectivamente había dos posturas al respecto, la que él llama de la tradición de primacía del legislativo, o autonomistas, que pretendía una elección indirecta basada en la representación proporcional, según el modelo gaditano, mientras que Iturbide proponía (tradición de primacía del poder ejecutivo) "una compleja combinación de representación corporativa y el número de partidos en cada provincia", habiéndose impuesto ésta última, a pesar de que la opinión mayoritaria de la Junta era la otra, y por lo mismo, habiendo producido ello mismo un desequilibrio regional y descontento en las provincias, lo que a la larga le costaría la existencia misma a este Primer Congreso Constituyente.

Así fue como el 17 de noviembre de 1821 se publicó en la Gaceta Imperial la convocatoria al Congreso Constituyente.

\section{LA CONVOCATORIA AL CONSTITUYENTE}

Para nosotros, dos siglos después, resulta un tanto cuanto extraño el método de elección de diputados constituyentes, a través de elecciones indirectas en tres grados; sin embargo era el sistema heredado de la Constitución de

7 Recordemos que en el Plan de Iguala no se había hecho mención de la soberanía popular.

8 Cfr. "Las Cortes mexicanas y el Congreso Constituyente", en Guedea, Virginia (coord.), La Independencia de México y el proceso autonomista novohispano 1808-1824, México, UNAM-Instituto Mora, 2001, p 287. 
Cádiz. En efecto, la carta gaditana preveía que la elección de diputados a Cortes se hiciera a través de juntas electorales de parroquia, de partido y de provincia (artículos 34 a 103; es decir, 69 de 384 que contenía dicha ley fundamental).

Así pues, la convocatoria mexicana preveía, primero, que el 16 de diciembre se publicaría por bando la indicción en las poblaciones que tuvieran ayuntamiento para que el día 21 del mismo mes, conforme al Reglamento expedido por las Cortes de España de 23 de mayo de 1812, todos los habitantes de los municipios (incluyendo extranjeros y castas) mayores de 18 años elegirían electores, los cuales, el día 24, deberían elegir alcaldes, regidores y síndicos de todos los ayuntamientos, a los cuales, el ayuntamiento saliente, les daría posesión el mismo día. Los cabildos seculares, así electos, a su vez, tenían la obligación, dentro de su seno, el día 27, de nombrar un elector de partido. Todos los electores de partido se tendrían que reunir en la capital del mismo, junto con los munícipes del ayuntamiento de la capital del partido, el 14 de enero siguiente, para escoger un elector de provincia, que podía ser munícipe o no. El día 28 del mismo mes, los electores provinciales, igualmente con los del ayuntamiento de la capital provincial, se juntarían en dicha capital de la provincia, bajo la presidencia del jefe político respectivo, o en su defecto el alcalde de primer voto del cabildo secular de la ciudad capital, para seleccionar el o los diputados que los representarían.

No cualquier persona podía ser elegido diputado, deberían de tener algunas de las siguientes categorías, dependiendo del número de representantes a que tenían derecho: un eclesiástico del clero secular, ${ }^{9}$ un militar, nacional o extranjero, un magistrado, juez de letras o abogado, un noble, un mayorazgo y otro de entre los profesionales de la minería, artesanos o comerciantes. Estaba previsto, según Alamán, que hubieran 162 diputados y 29 suplentes, porque según Iturbide, ${ }^{10}$ tenían que ser 172 , sin contar a los centroamericanos, que ascenderían a unos 20 más (no hace referencia a Chiapas que entonces era parte de Guatemala).

Así, pues, las provincias de México, Guadalajara, Veracruz, Puebla, Nueva Vizcaya, Sonora, Valladolid, Oaxaca, Zacatecas, San Luis Potosí,

9 En consecuencia quedaban excluidos los religiosos, lo cual dio pie a Iturbide de criticar la elección del padre Mier, lo que no sabía el entonces emperador depuesto es que Mier ya había sido exclaustrado.

10 Cfr. "Memoria ...", cit. p. 241. 
Guanajuato y Mérida de Yucatán, tendrían los tres de rigor (eclesiástico, militar y jurista), más aparte: la de México un minero, un título y un mayorazgo; la de Guadalajara, un comerciante; Veracruz, un comerciante; Puebla, un artesano; Nueva Vizcaya, un labrador; Sonora, un artesano; Valladolid, un labrador; San Luis Potosí, un empleado; Mérida, un empleado; y Guanajuato, un minero. En el entendido que Oaxaca y Zacatecas sólo tendrían los tres primeramente mencionados.

Tlaxcala, Nuevo Reino de León, Santander, Coahuila, Tejas, Nuevo México y las Californias, sólo tendrían un diputado de la clase que fuera. Querétaro, que no tenía rango de provincia, estaba en vías de serlo, propiamente no tenía diputados; sin embargo, enviaría sus electores a la ciudad de México para participar en la elección de los 28 representantes de la provincia de México, dentro de los cuales, dos se titularían "diputados de Querétaro" y de los 4 suplentes que dicha provincia nombraría, uno sería "de Querétaro". El número de los diputados por Chiapas y las provincias de Guatemala se dejaba para más adelante.

Nos llama mucho la atención la feroz crítica que el presidente del Consejo de Regencia, Agustín de Iturbide, esgrimiera en contra de la mencionada convocatoria, después de todo lo que presionó para que la hicieran a su modo (parece que más bien le interesaba la representación por clases), así nos dice: " "La convocatoria era defectuosísima..., no tuvo presente el censo de las provincias", ponía el ejemplo que a una que tenía 100,000 habitantes le daba un diputado y otra con 50,004 y que "los representantes debían estar en proporción de la ilustración de los representados" y no lo estuvieron, así como la elección la hicieran los ayuntamientos de las capitales y no la pluralidad de los ciudadanos.

Los diputados electos tenían que estar en la ciudad de México el 13 de febrero, a partir del 15 la Junta revisaría las credenciales de los presuntos diputados, para instalar el Congreso el día 24, aniversario del Plan de Iguala. Los diputados que tuvieran recursos propios no cobrarían salario, mientras que los que carecieran de ellos, las diputaciones provinciales tendrían que proporcionarles sus dietas. El Congreso, como señalamos antes, se dividiría en dos salas, integrándose por método de insaculación, de tal suerte que cada una se volvería la revisora de la otra (como apuntamos párrafos arriba, esto no se llevó a la práctica).

11 Cfr. Ibidem, pp. 227-229. 
En esta convocatoria se preveía también la elección de los integrantes de las diputaciones provinciales, las cuales se tenían que renovar; para lo cual se ordenaba que los electores provinciales, igualmente, con el ayuntamiento de la respectiva capital, al día siguiente; es decir, el 15 de enero de 1822, eligieran los siete vocales que cada diputación provincial debería contar.

\section{EL MOMENTO POLÍTICO PRECONSTITUCIONAL}

En este momento que se vivía en la naciente nación, tan delicado para su futuro, nos resulta interesante lo que nos informa Lucas Alamán, ${ }^{12}$ en varios sentidos: la presencia de $\mathrm{O}^{\prime}$ Donojú, y luego la gente que lo había acompañado desde España, y el impulso que dieron a la masonería, particularmente del rito escocés, fue concretado en tres puntos: apoyar el Plan de Iguala, propagar los principios liberales y excluir al clero de la instrucción de la juventud, a través de las llamadas escuelas lancasterianas; para lo cual, fundaron una logia llamada "Del Sol" y una escuela lancasteriana con el mismo nombre.

En otro sentido, el mismo Alamán, destaca: "El desprecio con que Iturbide veía á los antiguos insurgentes", excepto Guerrero, lo cual estaba claro desde los inicios mismos del movimiento iturbidista; lo que explica el intento de complot que se estaba dando en la casa del antiguo corregidor de Querétaro, Miguel Domínguez, en favor de establecer una república, junto con otras conspiraciones que se dieron más adelante; entre los conjurados en esta ocasión se encontraban Miguel Barragán, Guadalupe Victoria, Nicolás Bravo, Antonio López Matoso, Juan B. Morales, Miguel Borja, varios oficiales más y los sacerdotes Carbajal y Jiménez; ${ }^{13}$ confabulación que fue descubierta gracias a una delación de Pedro Celestino Negrete, desde Guadalajara, quien había sido invitado a sumarse al levantamiento. Los conjurados fueron apresados y al poco tiempo liberados, por orden de la Junta, excepto Victoria ( $\sin$ embrago, no tardó en fugarse), ya que se demostró: "que la conspiración se reducia á hablillas entre los que la habían formado, sin que contasen por entonces con medios algunos de accion”.

12

Op. cit., t. V, pp. 265-267.

13 Alfredo Ávila no coincide con esta información, pues asegura "Las primeras reuniones clandestinas se celebraron en casa del teniente Mariano Arriaga y de Miguel Domínguez... En casa de éste... concurrían los licenciados Antonio López Matoso, Juan Bautista Morales, el teniente Juan María García y un tal Velasco". Cfr. Para la libertad. Los republicanos en tiempos del Imperio 1821-1823, México, UNAM, 2004, p. 88. 
Nos dice Alfredo Ávila que:14 "El único objetivo claro de la conspiración era apresar a Iturbide y convocar cuanto antes un Congreso".

A partir de aquí, Alamán profundiza la idea del origen y desarrollo de los dos partidos, o bandos políticos, que se estaban conformando en ese momento en México: en primer lugar, estaban los ya referidos que sostenían el Plan de Iguala y los principios liberales, a los que se habían unido los españoles que no pensaban irse de México (pues en dicho Plan veían su "tabla de salvamento"), junto, paradójicamente, con los republicanos ("creían remoto el que aquel plan se llevase á efecto y temian la ambicion de Iturbide como peligro mas inmediato") y los antiguos insurgentes que odiaban al "generalísimo" por las razones antes señaladas. Por el otro lado, según el mismo Alamán, estaban Iturbide, el ejército, el clero regular y el pueblo (“á quien ganaba y entretenía con sus frecuentes pompas y funciones"); sin embargo, el propio don Lucas nos dice respecto a Iturbide: "el prestigio de su persona estaba destruido, y tres meses habían bastado para hacer un cambio completo en la opinión [pública]", y concluye señalando nuestro historiador "Estos eran los elementos que iban á entrar en el movimiento de las elecciones para el Congreso".

\section{PReparación del Congreso}

En la sesión del 6 de febrero de 1822, la Junta resolvió crear una nueva comisión, dentro de su seno, "que deba entender en los preparativos del Congreso", para lo cual, se nombró a los señores vocales Juan Francisco Azcárate, Juan José Espinosa de los Monteros y Francisco Manuel Sánchez de Tagle, la cual presentó su dictamen tres días después; o sea, el día 9, en el tenor siguiente: ${ }^{15}$

a) Se debería nombrar una comisión para que determinara el protocolo a cumplir durante la instalación del Congreso el día 24 del mismo mes, la cual presentó su minucioso dictamen (como era costumbre en esa época) el día 20 de febrero. ${ }^{16}$

b) Dentro de los ocho vocales de la Junta que habían sido electos diputados, se integraría una comisión de cinco de ellos para

${ }^{14}$ Cfr. Ibidem, p. 89.

${ }^{15}$ Cfr. Diario... cit., pp. 289 y 290.

${ }^{16}$ Ibidem, pp. 318-328. 
que examinaran los poderes de los demás presuntos diputados; reservándose a la Junta en pleno las demás atribuciones que la Constitución española (artículos 111 a 115) daba a la Diputación Permanente en proceso de renovación de las Cortes.

c) El presidente de la Junta, sólo o acompañado por otro vocal, publicaría las resoluciones de la misma.

d) Los secretarios de la Junta prepararían la secretaría del Constituyente.

e) Para integrar el quórum de instalación, se debería tener en cuenta a los diputados centroamericanos (la antigua provincia mayor de Guatemala), y

f) Siguiendo la tradición de las Cortes de Cádiz y del Congreso de Chilpancingo, si para el día 22 del mismo mes no había número suficiente de diputados para integrar quórum (la mitad más uno) la Junta nombraría diputados suplentes, los cuales actuarían hasta en tanto llegaran los correspondientes propietarios.

Los días 21, 22 y 23 del mismo mes de febrero, la Comisión de Examen de Poderes, presentó sus informes respecto a esta cuestión fundamental. Acto continuo, el pleno de la Junta procedió a declarar electos a los primeros diputados constituyentes. Con base en las actas de dicha Comisión y las actas de este primer Congreso Constituyente, haremos el esfuerzo de elaborar una lista de diputados constituyentes, en el entendido de que contienen errores y omisiones, ya que entonces las actas parlamentarias no se elaboraban con el cuidado como se hace en la actualidad; es decir, incluyendo listas de asistencia de congresistas, rara vez ponían el nombre completo y muchas otras sólo el segundo apellido. Hemos consultado la magnífica obra de Manuel González Oropeza, ${ }^{17}$ y también hemos encontrado algunos pocos errores, por lo tanto, en este listado ni están todos los que eran, ni eran todos los que estaban. ${ }^{18}$

17 Los diputados de la nación, México, Cámara de Diputados del Congreso de la Unión-Secretaría de Gobernación, 1994, 889 p.

18 Por ejemplo, tenemos los casos de Juan José Quiñones junto con López Plata, por León de Nicaragua, Manuel Gutiérrez Iturbide y Rubí por Honduras, Ambrosio Martínez de Vea, por Alta (Nueva) California y Ortiz de la Torre por la Antigua (Baja) California, Uraga por Guanajuato, José Miguel Riesgo, Antonio Iriarte, Elías González y Escalante por Sonora, Gómez Anaya por Guadalajara y Francisco Rivas, por Nuevo México, además de Diego Moreno, Pedro Lanuza, Agustín Iriarte por Zacatecas, Ortiz de la Torre por 
Así, pues, ponemos un asterisco (*) en aquellos casos que no aparecen en la Comisión de Poderes aunque sí en las actas del Congreso, mientras ponemos dos asteriscos $(* *)$ en caso contrario; es decir, aparecen en las actas de la Comisión pero luego no los vemos participando en el Constituyente. La explicación, creemos, está en la existencia de los "suplentes", de los cuales nunca se precisa la información en las fuentes impresas que hemos consultado, así como en los cambios que continuamente se estaban dando. Finalmente, diremos que en la Comisión de Revisión de Poderes de la Suprema Junta Gubernativa no se analizaron los casos de Chiapas y Yucatán, porque no habían concluido sus procesos electorales; sin embargo, dichas provincias sí acreditaron diputados con posterioridad, como en las provincias centroamericanas.

Diputados constituyentes de 1822

Por Chiapas:

Pedro Celis

Bonifacio Fernández de Córdova

Luciano Figueroa

José Anselmo Lara

Juan María Lazaga

Manuel de Mier y Terán

Marcial Zebadua.

Por Coahuila y Texas:

Refugio de la Garza

Antonio Elozúa (*) (suplente de Melchor Múzquiz, quien lo fue por México)

Por Durango ${ }^{19}$ (Nueva Vizcaya):

Baca y $\operatorname{Ortiz}(*)$ (no se menciona el nombre de pila)

Juan Pablo Caballero (*)

El obispo Juan Francisco de Castañiza Larrea y González de Agüero, marqués de Castañiza $(*)$

Baja California, Mayorga, Orantes, Larreinaga, Montufar y Beltranena y José Cecilio del Valle por Guatemala, Pérez del Castillo y Salvador Porras por Durango y Rodas , por mencionar sólo los que hemos visto.

19 Don José Miguel Ramón Adaucto Fernández y Félix, mejor conocido como Guadalupe Victoria, fue electo por Durango, pero no pudo tomar posesión en virtud de hallarse detenido y luego prófugo por su participación en las conspiraciones antes referidas. 
José Antonio de Castaños (*)

Rafael del Castillo

Manuel Espinoza (*)

Pablo Franco (*)

José Ignacio Gutiérrez $(*)$

Mariano Herrera (*)

Pedro Ignacio Iturribarría

Florentino Martínez (*) (tomó posesión el 24 de mayo de 1822)

José Ignacio Muguiro (*)

Gaspar Ochoa

José Ignacio Urquidi

Francisco Velasco $\left(^{*}\right)$

Villaloa $(* *)$ (no se menciona nombre de pila)

Manuel José de Zuloaga (*)

Por Guadalajara:

Santiago Alcocer

José Antonio Andrade

Bernardo Benítez Pérez (*)

Ignacio Cañedo

Joaquín Castañeda $(*)$

José María Covarrubias

Juan Pablo de Anaya (*)

Lino (Prisciliano) Fregoso (*)

Toribio González Moreno

Juan Martiarena (*)

Mariano Mendiola

José María Portugal y Pérez

José María Ramos Palomera

Prisciliano Sánchez (*)

Antonio José Valdés

Por Guanajuato:

Tomás Alamán

José María Bustamante

José Ignacio Espinosa (*)

Juan Ignacio Godoy

Antonio Mier y Villagomez

José Miguel Septién 
Vargas (**) (no se menciona nombre de pila)

Por Guatemala:

Flores (no se menciona nombre de pila)

Por México:

José Mariano Aranda

Francisco Barrera Carragal

Vicente Carbajal

Nicolás Campero

Manuel Carrasco

Manuel Cotero

Juan José de Acha

Juan de la Serna Echarte

Juan Antonio de Riba

José Ignacio Espinosa

José María Fagoaga

Antonio Eduardo Galicia (*)

José Goroztieta

Juan Horbegozo

Cayetano Ibarra

Martín Inclán

José María Iturralde

Francisco María Lombardo

Miguel Muñoz

Melchor Muzquiz

José Ignacio Nájera

Joaquín Obregón

Pablo Obregón

José Hipólito Odoardo

Francisco Ortega

José Agustín Paz

Joaquín Román

Francisco Manuel Sánchez de Tagle

Manuel Tejada

José Mariano Zardaneta y Llorente (segundo marqués de San Juan de Rayas) 
Por Nuevo León:

Juan Bautista de Arizpe $(*)$

Servando Teresa de Mier Noriega y Guerra (Fray Servando) (*) (tomó posesión hasta el 15 de julio, pues estaba preso en el castillo de San Juan de Ulúa, en Veracruz).

Por Nuevo México:

Francisco Pérez Serrano(*)

Por Nuevo Santander (Tamaulipas):

José Antonio Gutiérrez de Lara.

Por Oaxaca:

José Javier Bustamante

Juan Francisco Calderón

Carlos María de Bustamante

Antonio de León (*) (quien se incorporó después)

José Mariano de San Martín

Manuel Flores

Pedro Labairu

José Domingo Martínez Zurita

Antonio Morales de Ibáñez

Pando (**) (no se menciona nombre de pila)

José Román Ponce de León

Juan Sánchez del Villar (*)

Por Puebla:

Manuel Álvarez

Manuel del Callejo

Escusas $(* *)$ (no se menciona nombre de pila)

Joaquín Franco

Matías García (*)

Francisco García Cantarines

José María Jiménez

José María Lallabe (*) ( Entró a suplir a Matías García el 31 de mayo)

Rafael Mangino

José Mariano Marín

Antonio Montoya

José María Obando

Francisco Puig 
José Vicente Robles

Gabriel Torres

Por Querétaro:

Félix Osores.

Por San Luis Potosí:

Pascual (Manuel) de Aranda

José Joaquín Gárate

Ramón Esteban Martínez de los Ríos (*)

Juan de Dios Rodríguez (*)

José Mariano Sánchez Mora (Conde de Santa María de Guadalupe del Peñasco)

Alejandro Serratón (*)

Por Sonora y Sinaloa:

Carlos Espinosa de los Monteros(*)

Manuel Ximénez de Bailo(*)

Por Tlaxcala:

José Miguel Guridi y Alcocer.

Por Valladolid (Michoacán):

José María Abarca

Antonio Aguilar

Ansorena (**) (no se menciona nombre de pila)

Francisco Argandar

Camilo Camacho

José Antonio Castro

José María Carrera

Antonio Cumplido

Juan Nepumoceno Foncerrada y Soravilla

Ignacio Izazaga $(* *)$

Agustín Tapia

Mariano Tercero

Rudecindo Villanueva

Por Veracruz:

Manuel Argüelles

José María Becerra

Sebastián Camacho 
Rafael Leonardo de Echenique

Ignacio Esteva

José Joaquín Herrera

José Francisco Quintero (*)

Por Yucatán:

Tomás Aznar

Joaquín Castellanos y Díaz

Lorenzo de Zavala

Manuel Crescencio García Rejón y Alcalá

Manuel López Constante

Bernardo Peón

Juan Rivas Vértiz (*)

José María Sánchez

Francisco Antonio Tarrazo

Pedro Tarrazo

Fernando Valle

Por Zacatecas:

José María Bocanegra

Francisco García (*)

Valentín Gómez Farías (*)

Para tener una idea del talante de las personas electas para el Congreso Constituyente de 1822, recurrimos una vez más a don Lucas Alamán, ${ }^{20}$ quien nos dice que fueron nombrados muchos individuos, de los más considerados y estimables de cada población, algunos propietarios y comerciantes, siendo menor el número de eclesiásticos y abogados de los que se habían mandado a las Cortes de España, también se eligieron a algunos europeos, muchos de los antiguos insurgentes "y no pocos jóvenes poseídos de las teorías mas exageradas en materias políticas", también nos dice que "La mayoría de los nombrados profesaba las ideas liberales que dominaban entónces, y aunque divididos... entre los adictos á la monarquía con monarca de familia reinante, y los que aspiraban á un gobierno republicano, eran contrarios unos y otros á Iturbide, que no contaba en aquella reunión con muchos partidarios". Al respecto, en abono de la anterior opinión, la calificación que sobre los diputados entonces electos, nos señala el generalísimo Iturbide:

${ }^{20}$ Cfr. op. cit., p. 308. 
"Algunos hombres verdaderamente dignos, sabios, virtuosos, de acendrado patriotismo, fueron confundidos con una multitud de intrigantes presumidos y de intenciones siniestras". ${ }^{21}$

El propio Alamán nos dice:22 "tambien se habian hecho en Méjico las elecciones de los suplentes por los nativos de Goatemala, Yucatan y provincias internas hasta completar con ellos, segun lo acordado, el número de diputados necesario, para abrir las sesiones".

Un dato importante, que también nos lo trasmite Alamán, ${ }^{23}$ es que la Junta nombró comisiones de individuos dentro de su seno y fuera de él, que formasen los proyectos de códigos que habían de regir en la nación, lo cual no se verificó entonces ni después, en las varias ocasiones de éstas que han vuelto a nombrar, hasta mediados del siglo XIX. Dato interesante, no precisamente para la historia constitucional sino para la historia del derecho mexicano en general.

Por otro lado, en cuanto al final de la Junta, nos dice el mismo Alamán: ${ }^{24}$ "Habia concluido la junta todos los puntos principales para que habia sido convocada, y como suele acontecer con los cuerpos deliberantes considerados soberanos, que duran largo tiempo reunidos y cuyas facultades no están definidas, seguia ocupándose de otros de muy poca importancia y que no tocaban al poder legislativo ó debian dejarse al congreso" y más adelante continúa: "las sesiones se abrian tarde y con pocos individuos, porque todos se habian ido cansando y no recibiendo remuneracion alguna pecuniaria, preferian ocuparse de sus asuntos particulares mas que de los del público". Efectivamente, leyendo las actas de las sesiones de la Junta; ${ }^{25}$ se confirma lo dicho por don Lucas; y ahí mismo vemos cómo, después de que las ceremonias de instalación del Congreso Constituyente concluyeron el 24 de febrero de 1822, la Junta esperó las instrucciones de éste, siendo, lógicamente, que procedieran a disolverse cuando lo considerasen oportuno, pero siendo avanzada la hora, el vicepresidente citó para el día siguiente, cuando se

${ }^{21}$ Cfr. Manifiesto... cit., p. 231.

22 Ibidem, p. 310.

23 Ibidem. p. 302.

24 Ibidem, p. 296.

${ }^{25}$ Cfr. Diario de las sesiones de la Soberana Junta Provisional Gubernativa del Imperio Mexicano, instalada según previene el Plan de Iguala y Tratados de la Villa de Córdova, edición facsimilar tomada de la realizada en la Imprenta Imperial de D’Alexandro Valdés, México, UNAM, 1980, dentro de la colección Actas constitucionales mexicanas (1821-1824), t. I. 
acordó la efectiva disolución, disponiendo entregar su archivo, pero sobre todo los dos ejemplares de la Acta de Independencia, al Constituyente.

\section{AL AMANECER DEL 24 DE FEBRERO DE 1822}

Nos dice don Lucas Alamán: ${ }^{26}$ "El estrépito de la artillería y el festivo repique general de campanas, anunciaron á los habitantes de Méjico que en aquel dia... iba á instalarse el congreso". Así, a las siete de la mañana se reunieron en Palacio 102 diputados, y junto con la Junta Gubernativa y la Regencia, de dirigieron corporativamente a la Iglesia Catedral, se celebró la misa y acto continuo se procedió a otorgar el juramento de estilo, en donde los constituyentes se comprometieron a defender y conservar la religión católica, guardar la independencia de la nación mexicana y formar la constitución sobre las bases del Plan de Iguala y los Tratados de Córdoba, estableciendo la separación de poderes para que nunca pudieran reunirse en una sola persona o corporación. Concluyeron con el Te Deum y la Salve.

Posteriormente se dirigieron al antiguo templo de San Pedro y San Pablo, que a partir de ese momento se convertía en recinto legislativo. Ya ahí, bajo la presidencia provisional de don Carlos María de Bustamante y Manuel Argüelles como secretario, se procedió a elegir a las autoridades parlamentarias, resultando presidente don José Hipólito Odoardo, vicepresidente don Francisco Manuel Sánchez de Tagle y como secretarios el mismo don Manuel Argüelles y don Carlos María de Bustamante.

Inmediatamente se van a precisar muy importantes señalamientos:

Primera. Se declaraba instalado legítimamente el Soberano Congreso Constituyente Mexicano.

Segunda. La soberanía reside esencialmente en la nación mexicana.

Tercera. La religión católica, apostólica romana, con exclusión e intolerancia de cualquiera otra, sería la única del Estado.

Cuarta. Se adoptaba para el gobierno de la nación mexicana la monarquía moderada constitucional.

Quinta. Esta monarquía se denominará Imperio Mexicano.

Sexta. Se reconocía el llamamiento al Trono a los príncipes de la Casa de Borbón, conforme lo dispuesto en los Tratados de Córdoba.

${ }^{26}$ Cfr. Historia de Méjico, cit., t. V p. 314. 
Séptima. La soberanía nacional reside en el Congreso Constituyente; afirmación evidentemente mal formulada, ya que se contraponía con la segunda declaración; en el fondo, creemos, no se trataba más que de un problema de redacción.

Octava. El Constituyente se reservaba el poder legislativo, delegaba interinamente el ejecutivo en la Regencia ${ }^{27}$ (cuyos miembros tenían que prestar juramento) y el judicial en los tribunales existentes en ese momento.

Novena. El Soberano Congreso declaraba la igualdad de derechos civiles en todos los habitantes libres del Imperio, independientemente de su origen.

Décima. Se declaraba la inviolabilidad de los diputados constituyentes.

En la sesión del 26 de febrero, se tomaron también cuatro importantes acuerdos:

Primero. Se prorrogaba interinamente la jurisdicción de todos los tribunales y justicias hasta entonces establecidas, para que continuasen administrando justicia conforme a la legislación vigente.

Segundo. Igualmente, se ampliaba con carácter interino las atribuciones de las autoridades civiles y militares.

Tercero. Se ordenaba a todas las personas que ejercieran algún tipo de autoridad que hicieran el reconocimiento y juramento de obediencia al Congreso Constituyente, y

Cuarto. Que el Congreso tuviera tratamiento de "magestad", la Regencia de "alteza" y los tribunales la que tuvieran hasta esa fecha. Se disponía cómo tenían que ser promulgadas las disposiciones del Congreso, así como las preces que se deberían elevar a la Divinidad y que el Congreso emita un manifiesto público "sobre la justicia y necesidad de la independencia, y sobre la disposicion en que se halla de atender á todas las necesidades del imperio".

Al día siguiente, 28 de febrero, el cura Guridi recordó el ofrecimiento que de la Corona Imperial de México debería hacerse a Fernando VII y otros príncipes de la Casa Borbón, para lo cual, se nombró una comisión

27 Fueron cambiados por el Congreso, como miembros de la Regencia, Mons. Antonio Joaquín Pérez Martínez, Manuel de la Barcena y Manuel Velázquez de León, y puestos en su lugar el conde de Heras, Nicolás Bravo y Miguel Valentín. Según Iturbide: “ El congreso depuso a tres regentes, dejando sólo uno, reputado enemigo mio para reducir mi voto a la nulidad en el poder ejecutivo". Cfr. Memorias...cit., p. 236 
redactora del ofrecimiento, integrada por los diputados Echenique, Horbegoso, Espinosa y Fagoaga.

El 1o. de marzo de 1822, se dieron a conocer las comisiones parlamentarias y los diputados integrantes de las mismas nombrados por parte del presidente del Congreso, entre las que destaca la del Proyecto de Constitución, cuyos once miembros eran: Mariano Mendiola, José María Fagoaga, José Miguel Guridi y Alcocer, Toribio González Moreno, Rafael del Castillo, Francisco Manuel Sánchez de Tagle, Juan Ignacio Godoy, José de San Martín, Francisco García Cantarines, Ignacio Esteva y Cayetano Ibarra.

Al respecto, dice Alfredo Ávila, ${ }^{28}$ citando al diputado zacatecano José María Bocanegra, "Los ánimos estaban muy exaltados", y se hacían presentes, tres grupos con intereses políticos muy distintos: el de los viejos insurgentes, los iturbidistas y los borbonistas. De lo cual, ya hemos venido apuntándolo desde páginas atrás.

Nos dice Lucas Alamán ${ }^{29}$ que los diputados antiguos insurgentes (que se les inició a llamar "antiguos patriotas"), sus devotos y los que tenían poca inclinación a Iturbide o se oponían a sus ideas, de tendencia mayormente republicana, comenzaron a reunirse al interior del Congreso.

Por su parte, los borbonistas, eran de tendencia más liberal, eran españoles, estaban en favor del Plan de Iguala, en cuanto a traer a un Borbón, y simpatizaban con la Constitución de Cádiz, constituían mayoría en el Congreso, entre los que destacaban, los ya mencionados José María Fagoaga y Francisco Manuel Sánchez de Tagle, haciendo cabeza el primero, como señalamos antes. A ellos se debe aquella declaración de que la Regencia sólo cumpliría funciones ejecutivas, consideraban que su legitimidad se debía a la representación nacional que ostentaban, con lo cual pretendían negar su origen iturbidista, aunque no lo lograron.

Por otro lado, la intención de algunos españoles de revertir la independencia nacional ("rebelión de Juchi"), permitió a Iturbide fortalecer al ejército y aumentar sus atribuciones (por eso, nos dice el propio Ávila, que tal "rebelión", sospechaban los diputados contrarios al generalísimo, no era sino una farsa para allanar su camino al Trono). En fin, el caso es que las relaciones entre el ejecutivo y el Congreso se fueron haciendo muy tirantes, particularmente en la negativa de este último de darle mayores recursos económicos.

28 Op. cit., p. 93.

29 Op. cit., t. V, p. 324. 
En abono de lo anterior, recurramos a lo señalado por el propio don Agustín de Iturbide: 30 "empezaron a fomentar dos partidos irreconciliables que se conocieron después con los nombres de republicanos y borbonistas. Unos y otros tenían por objeto principal destruirme", luego agrega "Los borbonistas fueron mis enemigos", "no tenían por objeto el que reinase un Borbón en México, sino que volviésemos a la antigua dependencia"; claro, no hizo mayor referencia a los republicanos — era obvio lo que pretendíancomo tampoco mencionó a sus propios seguidores.

Así llegamos al 19 de mayo de 1822 en que Iturbide fue proclamado emperador de México, como veremos con detalle un poco más adelante; el caso es que la Comisión de Constitución no había presentado ningún proyecto, a pesar de los pronunciamientos que al respecto se habían hecho al interior del Congreso, parece que éste se había dedicado en casi tres meses a cuestiones menos trascendentes o francamente fútiles, y aquí tenemos el resultado; evidentemente la falta de experiencia política y, sobre todo, parlamentaria de estos constituyentes los había orillado a ello.

\section{AgUSTÍN I, EMPERADOR DE MÉXICO}

Como era de esperarse, las Cortes de España, en sus sesiones del 13 y 14 de febrero de 1822, no aprobaron los Tratados de Córdoba, los declararon "ilegítimos" y "nulos", en consecuencia, se dejaba insubsistente el artículo tercero de los mismos Tratados, el cual señalaba a las personas llamadas a ocupar el Trono de México y la correspondiente orden de prelación.

Por supuesto, dicho suceso movió las aguas al interior del Congreso. Al respecto, nos comenta Lucas Alamán, ${ }^{31}$ que "el partido republicano había adquirido mayor influencia y valentía" mientras que los "borbonistas, no se tenian por derrotados... ni creían que estaba agotado el plan de Iguala, que dejaba libre el camino de llamar á otro individuo de casa reinate" y por lo mismo se inclinaron en su mayoría en favor de que la Corona recayera en Iturbide, postura a la cual se sumó la mayoría del clero. Una minoría de los borbonistas, en cambio, se adhirieron a las fuerzas republicanas. A ello, nos dice el propio Alamán: "De estos partidos, el mas numeroso era el de los iturbidistas, pues en él entraban no solo los aspirantes á empleos, que todo lo esperaban de aquel que les debía el trono, y la mayor parte del ejército,

30 Cfr. "Memoria...", cit., pp. 226 y 227.

31 Op. cit., pp. 372-375. 
sino tambien la plebe de la capital, ganada por la pompa y las fiestas del generalísimo". En síntesis, como consecuencia de todo ello, es que finalmente quedaron sólo dos facciones en el Congreso: los republicanos, cuyo origen habían sido los antiguos patriotas, o sea, los antiguos insurgentes, un sector minoritario de los borbonistas de origen liberal, como ya señalamos, e inclusive algunos antiguos seguidores de Iturbide decepcionados con la conducta del generalísimo; mientras que por otro lado, estaban los iturbidistas que postulaban la asunción de Agustín de Iturbide al Trono Imperial de México.

Finalmente, explotó la bomba, en la noche del 18 de mayo de 1822, cuando un sargento del batallón de Celaya (el de Iturbide) llamado Pio Marchá, hizo tomar las armas a la tropa del mismo y proclamar por las calles el nombre de Agustín I, siendo imitados por los soldados de los demás cuarteles, de igual manera una turbamulta de "léperos" del barrio del Salto del Agua hacía lo propio, e incluso el coronel Rivero, ayudante de Iturbide, adentro del teatro hizo que los asistentes lo proclamaran como emperador. Cohetes, balas y campanas, ponían fondo a tal manifestación. Los contrarios al héroe de Iguala, se retraían, temiendo por sus vidas. En la residencia del presidente de la Regencia, reunidos varios de los principales hombres públicos del momento, "convencieron" a don Agustín para aceptar la Corona; uno de los presentes en dicha reunión, el presidente del Congreso, el diputado poblano doctor Francisco García Cantarines, convocó a dicho órgano parlamentario a las siete de la mañana del día siguiente, 19 de mayo, para que se tomaran las medidas oportunas.

Así llegamos a la mañana de aquél histórico día, en el antiguo templo de San Pedro y San Pablo, convertido, como dijimos antes, en sede del Soberano Congreso Constituyente, el cual estaba rodeado de una multitud de gente del pueblo que gritaba "viva Agustín I", ante tal desbarajuste, y ante la incapacidad de la presidencia de la augusta asamblea, se recurrió a la Regencia para intentar poner algún orden, y ésta respondió que ello no estaba en sus manos, por lo cual, se pidió la asistencia del mismo generalísimo, quizá no con tal propósito, sino más bien para presionar a los diputados a votar en favor del imperio iturbidista; por ello, cuando don Agustín decidió trasladarse en coche de caballos, éstos fueron retirados por el populacho, el cual empujó el vehículo; así el propuesto monarca llegó a la sede parlamentaria a las trece treinta horas, teniéndose a la multitud que lo acompañaba, militares y religiosos (dice Alamán que especialmente mercedarios), que inclusive, tuvieron que sentarse entre los diputados ya que 
se habían llenado las galerías; entonces Iturbide tomó la palabra exhortando al público a someterse a la decisión del Congreso, por la contra, dicho público exigía la inmediata proclamación del imperio iturbidista.

Se comenzó leyendo una petición de un grupo importante de jefes militares residentes en la ciudad capital, suscrita a las tres de la madrugada de ese mismo día, en la que señalaban:

Los regimientos de infantería y caballería del ejército imperial Mexicano existentes en esta capital, en masa y con absoluta uniformidad, han proclamado al serenísimo sr. Generalísimo Almirante, Presidente de la suprema Regencia D Agustin de Iturbide, Emperador de la América Mexicana. Este pronunciamiento se ha seguido con las demostraciones mas vivas de alegria y entusiasmo por el pueblo de esta capital, reunido aun en sus calles... y al mismo tiempo han creido su deber manifestar á V. M. esta ocurrencia; para que tomándola en consideracion, delibere sobre punto de tanta importancia. ${ }^{32}$

Se tenía duda de que hubiera quórum, pero, según las actas, se resolvió por la afirmativa pues se aseguraba había más de noventa legisladores.

A continuación tomó la palabra el célebre diputado tlaxcalteca, don José Miguel Guridi y Alcocer, quien, con mucho sentido común, expresó que los integrantes de dicha asamblea no tenían capacidad para tomar tan trascendente resolución, por lo cual propuso que los diputados ocurrieran a sus respectivas provincias a consultarlos sobre el particular. Inmediatamente después tomó la palabra el famoso canónigo oaxaqueño, de ilustre ejecutoria insurgente de la época de Morelos, don José de San Martín, a nombre propio y de los diputados José Ignacio Gutiérrez, Manuel Terán, José Mariano Anzorena y Francisco Rivas, para apoyar la propuesta de Guridi, además que se exigiera una mayoría de dos terceras partes del total de provincias y que mientras tanto, Iturbide quedara como único regente, y que se nombrase una comisión de trece constituyentes para que redactase un estatuto provisional que rigiese al país en tanto se resolviera la primera y fundamental cuestión. Se puso a votación dicha propuesta y fue rechazada por la asamblea.

Entonces se le dio la palabra al diputado Valentín Gómez Farías, quien presentó, a nombre de 47 legisladores, una propuesta para que, en virtud de que España no había aceptado los Tratados de Córdoba, quedaban rotos dichos Tratados y el Plan de Iguala, e invocando el artículo tres de los mismos

${ }^{32}$ Cfr. Actas del Congreso Constituyente Mexicano, reedición facsimilar tomada de la de Alejandro Valdés (México, 1822), cit., t. I, p. 280. 
Tratados (lo cual no dejaba de ser una incongruencia, ya que se invocaba la autoridad de un instrumento que se acababa de declarar "roto"), "votar porque se corone el grande Iturbide".

A continuación hizo uso de la palabra el diputado por Guadalajara, Antonio José Valdés, afirmando que él había sido el primero en defender los llamados a la casa Borbón para regir los destinos del Imperio Mexicano, "pero la conducta de aquella nación, aparece hasta el día la mas inconsecuente", por lo tanto, de conformidad con lo dispuesto en el artículo 3o., corresponde a las cortes - Parlamento - disponer la Corona mexicana, que él, hacía tres días, había querido llevarlo al seno del Constituyente; sin embargo, el presidente del Congreso, García Cantarines, se lo había impedido, por lo cual el mismo presidente lo interrumpió y lo invitó a leer la proposición, como en efecto así lo hizo. Dicha propuesta de declaración rezaba:

El Soberano Congreso Constituyente del imperio mexicano, en vista de los acuerdos de las córtes españolas, celebrados en las sesiones del 12 y 13 de febrero ultimo... la nacion mexicana queda desobligada respecto de la española en el contenido del art. 3 de los tratados de Córdoba... y de consiguiente, queda libre y expedita para resolver en este grave negocio, lo que convenga á su decoro, tranquilidad é intereses, ya sea con la misma dinastía por medio de un nuevo pacto ó de otro modo conforme á nuestras bases fundamentales.

En seguida, tomó la palabra el constituyente potosino Ramón Esteban Martínez de los Ríos, congratulándose por el Generalísimo "va á recibir el premio de su patriotismo y demas virtudes"; sin embargo, pedía "Obremos con prudencia, mexicanos: esta grande y magestuosa obra no es de momentos", y luego, con mucho sentido político: "No demos lugar á que digan las provincias que todo es efecto de la fuerza, de la sorpresa, ó de otros principios menos legítimos" y con más perspicacia aseguró: "No retardemos nuestro reconocimiento por los Estados Unidos, que tal vez lo dilataron considerando este acto vicioso é inmaduro". Entonces, la manipulada turba que ocupaba el recinto parlamentario se manifestó a través de "Un rumor sordo de desaprobacion que se oyó en las galerias enmudeció al orador". El "sr. Generalísimo" señaló: "Mexicanos: las reflexiones del sr. Martinez, son justas é hijas de la prudencia, y del buen juicio de (puntos suspensivos) el murmullo continuó", entonces el diputado Pedro Lanuza, poniendo orden, propuso dos puntos: anular el Plan de Iguala y los Tratados de Córdoba en lo relativo al derecho del rey de España y su familia "para coronarse en este 
imperio" y en consecuencia reside en el Congreso facultades legítimas para determinarlo, y después de fundamentarlo, concluye:

¿quién será el hombre singular, y que sin perjuicio ni reclamo de otro, merezca ceñir sus sienes con tan grandes laureles? Lo diré el virtuoso, el valiente, el caritativo, el humilde y sin igual hombre de los siglos, el señor don Agustin de Iturbide, que el Dios de la bondad lo destinó para romper á la Aguila las cadenas de fierro con que por tres siglos le hizo abatir sus alas el tirano de la España...

Y concluyó con otras palabras llenas de esa retórica tan propias del siglo XIX, y como dicen las Actas del Congreso (que hemos venido citando literalmente entre comillas) "El sr. Lanuza bajó de la tribuna con muchos aplausos de las galerias".

Los diputados Pascual de Aranda, de San Luis Potosí, y José María Portugal y Pérez, de Guadalajara, tomaron la tribuna y fueron de la misma opinión; mientras que el representante de Durango, José Ignacio Gutiérrez, pidió se analizara con más cuidado la propuesta que había formulado con don José de San Martín, que "han merecido el desprecio público" para que se "discuta suficientemente y con libertad" si tenían facultades para nombrar emperador de México a Iturbide; dicen lacónicamente las Actas "No se dio trámite á asta (sic) proposición". Por su parte el diputado José Agustín Paz, de la provincia de México, consideró que antes de dar la Corona al generalísimo, se concluyera la constitución, "Este discurso fue interrumpido por un murmullo de desaprobacion en las galerías", para lo cual, el diputado Valdés contestó a Paz que sus objeciones no tenían lugar.

Luego vinieron las opiniones de los diputados José María Covarrubias, de Guadalajara, y Francisco Argandar, de Valladolid, en el sentido de coronar a Iturbide. Luego, Francisco María Lombardo, de México, dijo, con mucho valor, frente a esa turba enardecida, que ese no era el día propicio para deliberar tan trascendentes cuestiones. Martínez de Vea y otros insistieron que ya no estaban obligados por el juramento por España. Rafael Mangino, de Puebla, insistió que primero había que consultar la "voluntad de las provincias" y la amplitud de los poderes de los diputados; Agustín Iriarte dijo que tenían los más amplios poderes para resolver todas las cuestiones relacionadas con la constitución de la nación conforme a Iguala y Córdoba. Melchor Múzquiz pidió se oyeran a las provincias, Valdés lo rebatió. "Seguidamente tomaron la palabra en medio del bullicio de las galerias, varios señores diputados; 
pero habiéndose restablecido el silencio se declaró el asunto suficientemente discutido", después que Iturbide llamó al orden y que se deberían someter a la decisión del Soberano Congreso, se puso a votación esta disyuntiva: "si se nombraria inmediatamente Emperador al sr. Generalísimo, ó se consultaría para el efecto á las provincias", todavía habló el diputado José Ignacio Gutiérrez, y se procedió a votar por escrito, y 67 votos sacó la inmediata proclamación y 15 por consultar a las provincias. Sobre el particular, las Actas aclaran que, aunque dichos votos sumaban 82 sufragios, "no son todos los diputados que se hallaban presentes, porque algunos salieron ántes de la votacion, unos fiados que habian firmado la proposición leida por el sr. Farias, la que creyeron suficiente para expresar su voluntad, y otros por que se hallaban esparcidos en los gabinetes de distraccion" con lo cual se pretendió salvar la opinión de que no existía quórum legal.

Acto continuo, el presidente del Congreso cedió el asiento bajo el solio a don Agustín de Iturbide y el populacho, congregado en San Pedro y San Pablo, durante un cuarto de hora estuvo aclamando al nuevo emperador de México y al Congreso Constituyente, hasta que aquél se retiró del recinto legislativo, levantándose la sesión por ahí de las cuatro de la tarde. ${ }^{33}$

Una breve reflexión: la novatez ganó a nuestros primeros políticos, fue tan obvia la manipulación de los partidarios de Iturbide, el desaseo político, como se diría hoy día, que estos mismos acontecimientos sirvieron de base para declarar posteriormente la nulidad de la designación de quien fuera llamado Agustín I, emperador de México. La duda sería, ¿sin este cochinero político en la sesión extraordinaria del Congreso Constituyente mexicano de 19 de mayo de 1822, se hubiera conseguido el mismo resultado?, jimposible saberlo!

No dejan de ser significativas las palabras de Lucas Alamán ${ }^{34}$ sobre este suceso:

Quedó, pues, nombrado D. Agustin de Iturbide, primer emperador constitucional de Méjico, como se nombraban los emperadores de Roma y Constantinopla en la decadencia de aquellos imperios, por la sublevacion de un ejército ó

33 Además, el 24 de mayo de 1822, el diputado Lanuza propuso que a don Agustín de Iturbide se le dio el título de "príncipe de Michoacán”, a su padre, don Joaquín, "duque de Iguala" y a doña María Nicolasa de Iturbide, "condesa de Córdoba y Orizaba", lo cual no agradó a don Agustín y al día siguiente la retiró.

34 Op. cit., t. V, p. 381. 
por los gritos de la plebe congregada en el circo, aprobando la eleccion de un senado atemorizado ó corrompido.

Por último, como dice Alfredo Ávila, ${ }^{35}$ con la exaltación de Iturbide al Trono imperial de México, se cortó el último y delgado hilo que todavía unía a México con España, al finiquitar la lejana posibilidad de que un príncipe Borbón ocupara dicho trono.

Para concluir este inciso, no nos resta sino apuntar que dos días después, el 21 de mayo de 1822, después de la una y tres cuartos de la tarde, como dicen las Actas, se presentó en la sede del Congreso el emperador electo, sentándose en su trono, y a su derecha el presidente de la asamblea, y después que éste dirigió unas breves palabras, Iturbide pronunció la fórmula de juramento y dio un pequeño discurso de acuerdo a la ocasión, el que finalizaba: "quiero, mexicanos, que si no hago la felicidad del Septentrión, si olvido algún día mis deberes, cese mi imperio".

\section{COMIENZA A ESTRUCTURARSE EL GOBIERNO}

Como era de esperarse, siendo el Congreso una asamblea constituyente, tenía la tarea prioritaria de estructurar al Estado; ya hemos visto como se formó la Comisión para el Proyecto de Constitución, por eso nos llama la atención que uno de sus miembros, el diputado Toribio González Moreno, a título personal, presentara en la sesión plenaria del 23 de mayo un proyecto para la creación de un Senado Conservador, junto con un Consejo de Estado, el Tribunal Supremo de Justicia y la organización del Ejército (todo parece e indica que "alguien" mandó al diputado González Moreno ${ }^{36}$ con tales proposiciones); ya se ve que la mentada Comisión nunca se reunía, como consta en Actas que en varias ocasiones hubo quejas al respecto, por eso se hizo ante el pleno. Así, pues, se mandó la propuesta a la citada Comisión, con carácter urgente, e incluso se pidió imprimiese dicho proyecto. El diputado Francisco Argandar sugirió darle prioridad al Consejo de Estado, pero Bocanegra fue de la idea que mejor la propia Comisión decidiera

35 Op. cit., p. 112.

36 Como se verá más adelante (con lo del Reglamento Provisional), este don Toribio parece que era el personero de Iturbide, pues presentaba iniciativas, aparentemente a título personal, pero realmente era lo que quería el emperador. 
lo más conveniente. ${ }^{37}$ Sobre este mismo particular, al final de la propia sesión de 23 de mayo, el presidente del Congreso, propuso se aumentase a quince el número de integrantes de la multicitada Comisión, para lo cual, se designaron a los diputados Francisco Argandar, Camacho (las Actas no señalan cual de los dos) y Antonio José Valdés.

Al día siguiente, 25 de mayo, se presentó, de manera muy rápida (obviamente), el dictamen correspondiente, para lo cual se señaló el día 29 para su discusión, como en efecto se llevó a cabo, continuándose los días 30 y 31 del mismo mes.

El Consejo de Estado, que tendría carácter de provisional, se integraría con trece individuos ${ }^{38}$ nombrados por el gobierno (o sea, el Poder Ejecutivo, integrado por los ministros del emperador) de entre una lista de treinta y nueve personas propuestas por el Congreso, siguiendo el modelo establecido por los artículos 231 a 241 de la Constitución española de 1812, aunque también se llegó a considerar la posibilidad de crear un organismo más parecido al Senado de los Estados Unidos; es decir, una cámara colegisladora del Congreso, idea que no prosperó.

La función más importante del Consejo de Estado, era opinar ante el gobierno de la constitucionalidad de las leyes que le remitiese el Congreso para su promulgación, así como sobre las relativas a las contribuciones, teniendo dicho gobierno un plazo de quince días para formular observaciones, si consideraba algún perjuicio en su cumplimiento, de tal manera que la volviera a discutir el Congreso, y si, previo dictamen de una comisión, insistiera, la devolvería al gobierno para proceder a su publicación.

En la sesión del 31 de mayo de 1822, se presentó la propuesta de creación del Tribunal Supremo de Justicia, integrado por cuatro ministros, siendo fiscal el último nombrado, debiendo ser electos por el Congreso. Se suscitaron sendas discusiones sobre el número de los integrantes y el método para su selección, no habiéndose puesto de acuerdo sobre ambos extremos, se regresó a la Comisión.

E13 de junio se presentó la lista de individuos postulados para el Consejo de Estado y para el día 18 se aprobó la relación de los propuestos al emperador, de entre los cuales fueron designados, el 22 del mismo mes, los titulares; al

37 Cfr. Actas..., cit., p. 325

38 Para funcionar válidamente se necesitarían la presencia de al menos nueve miembros. 
respecto, Lucas Alamán ${ }^{39}$ nos dice que fueron nominados "varios eclesiásticos y abogados de buen nombre" pero no dice exactamente quienes; se señaló a Negrete, "que era considerado como el segundo personage del imperio", como decano del Consejo, ya que la presidencia del mismo correspondía al emperador. El 1o. de julio, a las doce horas del medio día, rindieron ante el Soberano Consejo el juramento de ley.

Las personas designadas como consejeros de Estado fueron: ${ }^{40}$ Pedro Celestino Negrete, José Mariano de Almansa, Manuel Velásquez de León, Manuel de la Bárcena, Nicolás Bravo, Pedro del Paso y Troncoso, Vicente Simón González de Cossío, Florencio del Castillo, Tomás Salgado, José Nicolás Oláez, Rafael Pérez Maldonado, Mariano Robles y José Demetrio Moreno. Como secretario Juan Nepomuceno Gómez de Navarrete. Además se nombraron consejeros honorarios: José Manuel Bermúdez Sosaya, Manuel de la Peña y Peña, Manuel de Torres Valdivia y Juan Francisco Azcárate. ${ }^{41}$

Así llegamos al domingo 21 de julio de 1822 en que se llevó a cabo la coronación o consagración, como se decía entonces, del emperador Agustín I; quizá los historiadores han sido muy duros o quizá hasta crueles con esta parodia de monarquía, lo que sí es cierto se trataba de una institución que nos era ajena y el llamado emperador carecía en absoluto de las ejecutorias nobiliarias y personales para ocupar un puesto de esa naturaleza, como dice don Lucas Alamán: ${ }^{42}$

Era de data demasiado reciente la revolucion, para que su autor, por grande que fuese el mérito que en ella habia contraido, pudiese obtener aquel respeto y consideracion que solo es obra del tiempo y de un largo ejercicio de la autoridad. Los que pocos meses ántes habian tenido á Iturbide por su compañero ó su subalterno; la clase alta y media de la sociedad, que habia visto a su familia como inferior ó igual; no consideraban tan repentina elevacion, sino como un golpe teatral y no podian acostumbrarse á pronunciar sin risa los títulos de príncipes y princesas.

La ceremonia tuvo un carácter eminentemente religioso, como la de los reyes europeos en la Edad Media, actuando como consagrante el obispo de

39 Op. cit., t. V, p. 388.

40 AGN. Gobernación (127-128) caja 36, exp. 4, 18 de noviembre de 1822.

41 El Consejo de Estado fue suprimido por el Congreso Constituyente el 18 de abril de 1823 .

42 Cfr. Ibidem, p. 403. 
Guadalajara, el insigne y caritativo don Juan Cruz Ruiz de Cabañas y Crespo, estando presentes los mitrados de Puebla, Durango y Oaxaca, habiéndose excusado el de Sonora, correspondiendo pronunciar el respectivo sermón a nuestro ya conocido obispo de Puebla, monseñor Antonio Joaquín Pérez Martínez. El arzobispo de México, don Pedro José de Fonte, desde el año anterior había abandonado a la grey a él encomendada, retirándose a España, sin renunciar a su mitra hasta 1838 , por lo tanto no asistió.

Recurramos nuevamente a aquel testigo cualificado de aquellos sucesos, don Lucas Alamán:43 "Esta funcion sin embargo estuvo lejos de llenar el objeto de los que con tantoempeño la promovieron, pues no solo no dio, con la sancion de la religión, mayor respeto al nuevo órden de cosas, $\sin [\mathrm{o}]$ que mas bien contribuyó á quitárselo".

Poco podemos añadir a lo hasta aquí dicho.

\section{LOS PROYECTOS CONSTITUCIONALES DE ESTA ÉPOCA}

La pregunta que por supuesto se nos plantea es ¿Qué se había adelantado del texto constitucional? Parece que no mucho. Don Ernesto de la Torre Villar, de grata memoria, junto con el distinguido constitucionalista e historiador guatemalteco, quien residió varios años en México, habiendo llevado a cabo, durante esos años, una importante producción científica, Jorge Mario García Laguardia, escribieron un libro muy interesante que nos ayuda a entender el momento histórico constitucional que estamos estudiando; nos referimos a Desarrollo histórico del constitucionalismo hispanoamericano, ${ }^{44}$ en el que nos informan de los proyectos de leyes fundamentales que se elaboraron en esta época, iniciando con los que ellos llaman "El proyecto de Valdés".

No nos queda muy claro de lo que están hablando. Dicen, citando una Circular del 13 de julio de 1822, que el Congreso formó una comisión para elaborar un proyecto de constitución, y dan los nombres de sus integrantes; sin embargo, ya dijimos que desde el 1o. de marzo de ese año se había nombrado la comisión parlamentaria para redactar el proyecto de ley suprema, con 11 diputados, que el 23 de mayo se nombraron tres más, empero, no coinciden con la Circular de 13 de julio de 1822, citada por De la Torre y García Laguardia, en la misma se menciona al doctor Herrera, que no era constituyente en ese momento, sino secretario de Relaciones.

43 Idem.

44 México, UNAM, 1976, 314 pp. 
Pues bien, un miembro de esta Comisión, Antonio J. Valdés, presentó un documento denominado Constitución del Imperio o proyecto de organización del Poder Legislativo, presentado a la Comisión actual de Constitución por... , el que obviamente se refería exclusivamente al poder legislativo, y como dicen los autores citados. "No conocemos las otras partes de la Constitución; por lo tanto, no podemos presentar la trama entera de la misma". ${ }^{45}$

Luego se refieren al Proyecto de Constitución presentado a la Comisión de ella por uno de los individuos que la componen, ${ }^{46}$ aunque no se menciona autor ni fecha exacta de presentación, los autores que venimos comentando se la atribuyen a don José Manuel de Herrera, lo cual nosotros, con el debido comedimiento, no lo compartimos; en primer lugar, como ya señalamos, Herrera no era diputado sino secretario de Relaciones, además que no hay ningún dato objetivo en el Proyecto en cuestión que permita colegir tal aserto.

Por su parte, Manuel Calvillo, ${ }^{47}$ citando la autoridad de don Carlos María de Bustamante, se lo atribuye al antiguo diputado gaditano, ahora constituyente mexicano, don Miguel Guridi y Alcocer, aunque no de manera contundente ya que dice Calvillo "se cree"; aunque en nuestra modesta opinión suena más lógico. El mismo Calvillo postula que este proyecto fue redactado entre abril y mayo de 1822 .

Se trata, no cabe duda, de un buen documento, muy importante y elogiado por De la Torre y García Laguardia, el cual, como tantos otros, no ha sido debidamente estudiado. Reproducido íntegramente en la magnífica obra de Manuel Calvillo antes citada. Si realmente Guridi es su autor, como parece que lo fue, refleja en el texto su alta formación intelectual, teológica y jurídica, y sobre todo su experiencia, primero como diputado constituyente en Cádiz, miembro de la Junta Suprema Gubernativa, ahora diputado en el primer Constituyente, así como en la Junta Nacional Instituyente, luego en el segundo Constituyente y legislador ordinario. Es una redacción moderna para su época, en sus 125 artículos aborda, primero, la parte orgánica y luego la dogmática; se nota la vena docente del autor, su estilo fluido y explicativo de los conceptos utilizados nos acreditan la gran fama de orador sagrado que alcanzó tanto en Puebla-Tlaxcala, como la ciudad de México. Los últimos seis artículos del proyecto, correspondientes al título cuarto de la segunda parte,

45 Ibidem, p. 85.

${ }^{46}$ Impreso en la Oficina de D. José María Ramos Palomera, México, 1822, 40 p.

${ }^{47}$ Cfr. La República Federal Mexicana. Gestación y nacimiento, 2a. ed., El Colegio de México-El Colegio de San Luis, 2003, pp 325-329 y 627 y ss. 
referentes a la instrucción pública, son todo un himno a su vocación de ilustrado de finales del XVIII y principios del XIX, particularmente la educación de los niños indígenas y las universidades, todos conducidos por una instancia gubernamental que se denominaría "dirección general de instrucción pública", "compuesta de los hombres más instruidos". No resistimos la tentación de copiar el artículo 120 de este Proyecto: "Es obligación de los individuos de la sociedad y de la que en gran parte dependen las demás, el estar impuestos en sus derechos y deberes, y en el ramo en que cada uno le sirve, a cuyo fin debe promoverse la instrucción pública tan interesante al bien común".

Ojalá que pronto se le preste la atención que se merece y se lleve a cabo el estudio o estudios adecuados de este Proyecto.

Por último, el mismo Calvillo, nos informa de un tercer proyecto, dentro de la etapa iturbidista, redactado por el antiguo diputado gaditano José María Couto y fechado en Valladolid el 8 de enero de 1823, con el título de "Constitución del Imperio Mexicano", cuyo original se encuentra en Iturbide Papers de la Biblioteca del Congreso de los Estados Unidos y que conocemos en México gracias a la publicación que del mismo hiciera el citado Manuel Calvillo, en el estupendo libro que venimos citando.

\section{X. "EXAMínese Lo Que hizo el CONGRESO"}

Su objeto principal era formar la constitución del Imperio, ni un solo renglón se escribió de ella" nos dice el emperador fallido, ${ }^{48}$ y continúa un poco más adelante "Las discusiones se redujeron a fruslerías de ninguna importancia, y si alguna versó sobre materia digna, fue al menos impertinente porque no era la ocasión de tratarla" y sigue "Ni reglamento interior se formó", y páginas más adelante "Con mi subida al trono parecía que se había calmado las disensiones, pero el fuego quedó cubierto, y los partidos continuaban sus maquinaciones; disimularon por poco tiempo y volvió a ser la conducta del congreso el escándalo del pueblo. Tuve denuncias repetidas de juntas clandestinas habidas por varios diputados para formar planes que tenían por objeto trastornar el gobierno jurado por toda la nación" y concluye: "El 26 de Agosto mandé proceder a la detención de los diputados comprendidos en las denuncias, y contra quienes había datos de ser conspiradores ... [lo cual] fue aprobado en todas sus partes por el consejo de Estado". Todo lo

${ }^{48}$ Cfr. "Memorias...", cit. pp. 231, 233,242 y 243. 
cual, posteriormente fue justificado por el recién resignado emperador en estos términos: "La representación nacional ya se había hecho despreciable por su apatía en procurar el bien, por su actividad en atraer males, por su insoportable orgullo, y porque había permitido que individuos de su seno sostuviesen en sesiones públicas, que ninguna consideración debían tener del plan de Iguala y tratados de Córdoba".

Rebasaría los límites y objetivos de este trabajo relatar la conspiración republicana de 1822, para todo caso, remitimos a los lectores interesados al libro de Alfredo Ávila, ya citado en páginas previas, ${ }^{49}$ de factura reciente, que nos parece adecuado para ese fin.

Como era lógico, una situación tan rara y compleja como fue la exaltación al Trono Imperial de México, de quien apenas unos meses antes no era más que un coronel en retiro del ejército realista, en una nación que apenas nacía al concierto mundial de Estados independientes, y sin una auténtica tradición monárquica, ya que en la época virreinal, el rey se situaba a muchos miles de kilómetros, prácticamente nadie lo conocía, no existía una auténtica Corte, la escasa nobleza era más de oropel que efectiva ya que sus títulos habían sido comprados y no obtenido por méritos personales; como hemos descrito en páginas anteriores, había surgido una oposición republicana, los antiguos insurgentes, frente a un iturbidismo que respondía más a simpatías personales o lealtades castrenses que a convicciones.

Eran varios los frentes en contra del Imperio de Iturbide, desde el parlamentario, en donde eran incapaces de proporcionar recursos económicos al gobierno, así como la discrepancia respecto al método para elegir a los magistrados del Tribunal Supremo, ya que ambos poderes, Legislativo y Ejecutivo, se arrogaban dicho derecho, junto con conspiraciones militares que hallaron su sinergia en la destacada figura de don Guadalupe Victoria (recordemos como ya había estado inodado en otro movimiento subversivo que hasta la cárcel lo había llevado y le había impedido tomar posesión de su lugar en el Congreso Constituyente para el que había sido elegido por Durango); y por supuesto, distinguidos publicistas, como se decía entonces para designar a los hombres públicos o políticos, y pensadores. Por su parte, los partidarios de don Agustín no se quedaron ni callados ni con los brazos cruzados y respondieron con un enfrentamiento, a veces soterrado, a veces público, que vino a hacer crisis el 1o. de agosto de 1822 . 
En efecto, se dio cuenta al Consejo de Estado de lo que estaba sucediendo en el país y al día siguiente, el propio emperador, compareció ante el mismo Consejo para exponer que no se podían tolerar todas esas traiciones al Plan de Iguala, ni por parte de los republicanos, ni de los absolutistas. Lo que motivó la Consulta del gobierno al soberano congreso sobre que se establezca un tribunal especial en esta corte y demás capitales de provincia, dedicado a juzgar exclusivamente las causa de sedición contra el Estado, el cual llevaba la fecha del 4 del mismo mes. Iniciativa que fue turnada a las comisiones de Constitución y Legislación para su análisis, con el resultado negativo, como era de esperarse, por el Constituyente, el día 12. Como dice el propio Ávila: "La disputa por los poderes continuaba, pero en esta ocasión la balanza se inclinaba en favor de Iturbide... la oposición sólo podía recurrir al secreto: se volvieron conspiradores". ${ }^{50}$ El mismo Ávila nos dice: ${ }^{51}$

La historiografía que admite la existencia de la conjura de agosto de 1822 está de acuerdo en que iba a estallar una rebelión en contra de Iturbide hacia la tercera semana de ese mes, aunque no siempre se le da el crédito de poder derrocar al régimen. Al parecer, Agustín de Iturbide actuó a tiempo para detenerla.

Como resultado de ello fue el arresto de sesenta personas, incluidos diecisiete diputados ${ }^{52}$ y muchos militares: por supuesto, el Congreso pidió explicaciones ya que se consideró como ilegal la detención de diputados, a lo cual, el secretario y el subsecretario de Relaciones Interiores y Exteriores, los viejos insurgentes José Manuel de Herrera y Andrés Quintana Roo, se manifestaron en contra ya que, según ellos, el fuero legislativo sólo se refería a delitos de opinión y en la especie se trataba de ilícitos contra la seguridad del Estado. Por supuesto, tales aprehensiones causaron un gran impacto en la opinión pública y particularmente entre los republicanos, quienes los consideraban inocentes. El 2 de octubre fue detenido también el profesor

50 Op. cit., pp. 130 y 131.

51 Ibidem, p. 153.

52 Entre ellos, había constituyentes tan importantes como Carlos María de Bustamante, Manuel Carrasco, Juan Echarte, Rafael Echenique, José María Fagoaga, Ignacio Gutiérrez, José Joaquín Herrera, José María Iturralde, Juan María Lazaga, Francisco Lombardo, el P. Mier, Pablo Obregón, Francisco Sánchez de Tagle, Francisco Tarrazo, Marcial Zebadúa y los centroamericanos Juan de Dios Mayorga y José Cecilio del Valle. Previamente había sido detenido José María Bustamante y posteriormente Juan José Acha, Juan Pablo Anaya, Santiago Baca, Santiago Milla y Anastasio Zerecero. 
del Colegio de San Ildefonso de la ciudad de México, doctor José María Luis Mora, al considerársele parte de la conspiración.

De acuerdo con la legislación gaditana, antes de poder juzgar a los congresistas, éstos tenían que ser desaforados por el propio Congreso; sin embargo, ante las dudas legales y de facto, por la situación de transición que vivía el país, se decidió que fuera el Consejo de Estado quien los juzgase, organismo al cual fueron consignados el 16 de noviembre de 1822. Para el 20 de diciembre sólo quedaban veintiséis detenidos, en los conventos de Santo Domingo, San Francisco y San Hipólito de la ciudad de México, el resto había sido liberado por el emperador, con la opinión favorable del Consejo.

Como era de esperarse, la molestia de los diputados al Congreso Constituyente iba en aumento, así como los rumores de una inminente disolución del mismo, por lo cual, algunos de sus miembros empezaron a abandonar la capital del Imperio; por ello, a finales de septiembre de 1822, ya no era posible alcanzar el quórum; para esto, Lorenzo de Zavala y otros legisladores presentaron el día 25 de ese mes, un Proyecto de reforma con el fin de reducir el número de representantes e integrar una segunda cámara, según el plan original aprobado por la Soberana Junta Gubernativa; propuesta que no fue mal vista por el emperador; por tal motivo, convocó el 16 de octubre a varios diputados y generales con el fin de discutir dicho plan, y al no llegar a ningún acuerdo, se volvieron a reunir al día siguiente varios diputados, los miembros del Consejo de Estado y altos cargos del ejército; así, después de las doce horas, nos informa Alfredo Ávila, ${ }^{53}$ enviaron al secretario de Relaciones, José Manuel de Herrera, al Congreso para solicitar se aprobara el Plan, junto con el establecimiento de tribunales militares para juzgar delitos de subversión y se reconociera que la legislación gaditana estaba vigente para los tres poderes; el Congreso respondió el día 19, admitiendo la vigencia de la legislación gaditana, pero no así el establecimiento de los tribunales militares para tal propósito; Iturbide quiso, además, que se le reconociera el derecho de veto para la próxima constitución imperial, lo cual tampoco fue aceptado.

Ante todo ello, el emperador decidió cortar por lo sano y el 31 de octubre mandó a Luis Cortázar a notificar al Congreso que había decidido disolverlo, sustituyéndolo por una Junta Instituyente integrada por dos representantes por cada provincia, sumando un total de 55 miembros y ocho suplentes,

53 Op. cit., p. 219. 
la cual debería iniciar sus sesiones el 2 de noviembre siguiente. ${ }^{54}$ Todo ello, lógicamente, empezó a provocar inquietud al interior del país, y a levantarse voces con el objeto de establecer una república, movimientos subversivos encabezados fundamentalmente por los viejos insurgentes, aquellos que habían sido excluidos sistemáticamente por don Agustín y ahora su participación resultaba definitiva; dentro de los cuales destaca el Plan de Veracruz, redactado por el intrigante representante de Colombia en México, Miguel Santa María y firmado por Antonio López de Santa Anna en dicho puerto el 2 de diciembre de 1822, aunque proclamado el día 6, al cual se adhirió don Guadalupe Victoria. ${ }^{55}$ Por supuesto, en los movimientos republicanos tuvieron una importante participación los recién aparecidos masones, por lo pronto de rito escocés, ${ }^{56}$ fundados por Mariano Michelena.

De esta forma, don Agustín I, emperador de México, había matado y enterrado al incipiente constitucionalismo de nuestra patria recién independizada.

\section{Y VOLVEMOS A EMPEZAR}

El 2 de noviembre de 1822, en el antiguo templo de San Pedro y San Pablo, ahora convertido en recinto legislativo, como señalamos antes, a las cinco y media de la tarde, bajo la presidencia del obispo de Durango, Marqués de Castañiza, por ser el de mayor edad, se reunieron los señores designados como miembros de la Junta Nacional Instituyente:

1. Joaquín Román,

2. El Marqués de Rayas,

3. Francisco Puig,

4. Miguel Guridi y Alcocer,

5. Francisco Argandar,

6. Antonio Aguilar,

54 Según Iturbide, en su Memoria (p. 245) el encargo de esta Junta estaba limitado a formar nueva convocatoria y ejercer las funciones legislativas en casos urgentes.

55 Comenzó siendo un conflicto personal entre Santa Anna y José Antonio de Echávarri, y concluyó siendo un levantamiento en favor de la república.

56 Cfr. Vázquez Semadeni, María Eugenia, La formación de una cultura política republicana. El debate público sobre la masonería, México, 1821-1830, México, UNAMEl Colegio de Michoacán, 2010, p. 43. 
7. Antonio Morales de Ibáñez,

8. Pedro Labayru,

9. Francisco Uraga,

10. Antonio Mier y Villagomez,

11. José María Becerra,

12. Toribio González,

13. Mariano Mendiola,

14. El Marqués de Castañiza (obispo de Durango),

15. Francisco Velasco,

16. Ramón Esteban Martínez de los Ríos,

17. Pascual de Aranda,

18. Agustín de Iriarte,

19. José María Bocanegra,

20. Carlos Espinosa de los Monteros,

21. Antonio Iriarte,

22. Lorenzo Zavala,

23. El Conde Miraflores,

24. Francisco Pérez Serrano,

25. Juan Bautista Arizpe,

26. José Antonio Gutiérrez de Lara,

27. Antonio Elozua,

28. Refugio de la Garza,

29. Manuel Ortíz,

30. Ambrosio Martínez de Vea,

31. Pedro Celis,

32. Isidro Montúfar,

33. Luciano Figueroa,

34. Manuel Ignacio Gutiérrez,

35. Bonifacio Fernández,

36. Miguel Larrainaga,

37. Tomás Veltranena,

38. José Vicente Orantes,

39. Juan José Quiñones,

40. Manuel López de la Plata,

41. Antonio José Valdés,

42. José María Covarrubias,

43. Manuel Flores, 
44. Martín Inclán,

45. José María Abarca, y

46. Mariano Aranda

No habiendo asistido, aunque estaban nombrados: Luis Mendizábal, Juan Nepomuceno Mier y Altamirano, José Ignacio Esteva, Salvador Porras, Pedro Arrollave, José Francisco Peralta, Jacinto Rubí, Simón Elías González y Manuel Álvarez, en total nueve más, con lo cual hacían los 55 mencionados.

A continuación se presentó el emperador, acompañado por sus secretarios de despacho, consejeros de Estado, generales residentes en la capital y la consabida muchedumbre que solía sumarse a estos actos formales, un poco teatrales. Luego vino el discurso de ocasión por parte de Iturbide, la lectura de las Bases Orgánicas de la Junta Nacional Instituyente (decretadas por el mismo emperador), por parte del secretario de Relaciones y el juramento de los miembros de la Junta en el que prometieron ser fieles al emperador, desempeñar las obligaciones propias del encargo y cumplir las Bases Orgánicas mencionadas. Castañiza nombró secretarios provisionales y se eligió mesa directiva de la Junta: presidente, el propio Marqués de Castañiza, primer vicepresidente, Toribio González, segundo vicepresidente, Mariano Mendiola, primer secretario, Antonio Mier y Villagómez, segundo secretario, Juan José Quiñones, tercer secretario Antonio José Valdés, y cuarto secretario, Juan Bautista de Arizpe. Habiéndose levantado la sesión a las nueve y cuarto de la noche.

Así empezó este nuevo experimento legislativo, que como dice José Barragán ${ }^{57}$ fue "el postrer intento de Iturbide por consolidar su trono con la ayuda fundamentalmente de los diputados afectos a su persona y a sus planes", ensayo que habría de fracasar pocos meses después ya que para el 6 de marzo de 1823 hubo de ser clausurado, por el triunfo del primer cuartelazo que se dio en nuestra Patria: Casa Mata. Pero, vayamos por partes.

Es importante que conozcamos el contenido de las Bases para entender bien el funcionamiento de la Junta. Como primera función era elaborar un proyecto de constitución del Imperio, para lo mismo se le dio facultad de expedir una "ley orgánica" (sic) en la que se reglamente la forma de convocar al congreso constituyente así como la manera de discutir, decretar y sancionar la propia ley suprema, siempre en concordancia con el Gobierno (se decía que en todas las discusiones se admitirían los oradores que enviara

${ }^{57}$ Cfr. "Introducción", Actas... cit., t. VII, p. VII. 
el gobierno, después de la poca gratificante experiencia tenida con la Suprema Junta Gubernativa y el Congreso Constituyente recién disuelto). De igual manera, se facultaba a la Junta Nacional Instituyente a expedir un reglamento para su gobierno interior. Se señalaba que conservaría el ejercicio del poder legislativo, pero sólo para asuntos urgentes y tendría la misión de organizar el Plan de Hacienda Pública (también de acuerdo con el Ejecutivo) con el objeto de hacerse de los recursos necesarios para sufragar los gastos del Estado.

Efectivamente, la Instituyente trató lo relativo a varias materias, como la fiscal, la de colonización y la justicia penal, Reglamento Interior de la Junta, emisión de papel moneda, limitaciones a la libertad de expresión, pero indiscutiblemente, la más importante fue la relativa al intento de la expedición de un Reglamento Provisional Político del Imperio Mexicano. Lo primero que nos llama la atención de éste, es que en las Bases Orgánicas que expidió el propio Iturbide, no se hubiera atribuido a la Junta la facultad de aprobar ningún reglamento provisión del Imperio.

En el Diario de la Junta Nacional Instituyente del Imperio Mexicano ${ }^{58}$ consta que se formó al interior de la Junta una Comisión para redactar el proyecto en cuestión, la cual estaba integrada por nuestro ya conocido Toribio González, además de Antonio J. Valdés y Ramón Martínez de los Ríos, los cuales a su vez eran miembros de la Comisión de Constitución y Convocatoria, con ello, pensamos, quizá hubiera sido una subcomisión de ésta. ${ }^{59}$ Pues bien, esta Comisión especial para el reglamento concluyó su trabajo el 18 de diciembre de 1822, presentado el mismo el día 31 del propio mes, mandándolo imprimir y comenzado a discutir el 10 de enero de 1823. Como demuestra José Barragán, ${ }^{60}$ el Reglamento Provisional del Imperio nunca se acabó de aprobar, aunque hay opiniones en sentido afirmativo, el cuartelazo de Casa Mata triunfó antes.

58 En Actas constitucionales mexicanas (1821-1824), cit., t. VII.

59 Barragán analiza el tema de la autoría del Proyecto y concluye que fueron esos tres integrantes de la Junta (cfr. "Introducción", cit., pp.XVI y XVII) y nosotros coincidimos con él.

60 Ibidem, pp. XVII-XXVII. 


\section{El Proyecto De Reglamento Provisional POLÍTICO DEL IMPERIO}

En el exordio del Proyecto, o "exposición de motivos" como diríamos hoy en día, se explican con mucha claridad las razones que llevaron a plantear un instrumento jurídico de tal naturaleza:

a) Porque la Constitución española era la norma suprema de la nación que nos habíamos emancipado,

b) Porque la misma ley suprema había sido causa de "horribles turbulencias y agitaciones" allende los mares,

c) Porque sus disposiciones eran inadaptables a nuestros intereses, costumbres y circunstancias, $\mathrm{y}$

d) La más importante para ellos: el emperador había "manifestado la urgentísima necesidad que tenemos de un reglamento propio para la administracion, buen órden y seguridad interna y externa del estado, mientras que se forma y sanciona la Constitucion política".

Dicho en otras palabras, a Iturbide le estorbaba más que ayudaba la Constitución de Cádiz, aún como norma supletoria, y así fue como la Junta Nacional Instituyente acordó sustituir dicha carta gaditana por este Reglamento Político Provisional. Dicha decisión no fue nada fácil de tomar, varios miembros de la Junta, encabezados fundamentalmente por el yucateco Lorenzo de Zavala, se oponían a ello, alegando una razón fundamental: la Junta no tenía facultades para derogar la Constitución española, cuya vigencia había sido proclamada por los textos fundamentales que hasta ese momento seguían rigiendo nuestra patria, como lo eran el Plan de Iguala y los Tratados de Córdoba y por ende, tampoco tenían facultad de expedir un reglamento político provisional.

En efecto, desde el 10 de enero en que se presentó el Proyecto de Reglamento, se empezaron a discutir esas cuestiones, hasta el 14 de febrero del mismo año de 1823, en que se votó si estaba discutido suficientemente el asunto y por consecuencia si se aprobaba, en lo general, dicho Proyecto; habiendo votado por la afirmativa 21 miembros de la Junta, frente a 16 que votaron por la negativa, entendieron que estaba aprobado en lo general.

Para el que esté interesado en la lectura de esas 175 páginas impresas del Diario de la Junta (pp. 221 a 396) resulta muy sugestiva; a nosotros lo que nos llama la atención es que los miembros de la Junta, habiendo sido 
designados por Iturbide y sabiendo que el emperador estaba interesado en ello, ${ }^{61}$ varios de ellos se opusieron a la expedición del Reglamento, por razón de sus principios, no por mezquinos intereses políticos de la circunstancia. Otra cuestión digna de tenerse presente es, aunque se había derogado la Constitución de 1812, la legislación ordinaria que de ella se derivó, continuó en vigor, con lo cual la técnica constitucional legislativa utilizada no quedaba muy bien parada. ${ }^{62}$

Reanudado el debate, ahora en lo particular, realmente lo único que se sometió a discusión y fue aprobado sin oposición fue el nuevo exordio, que subsumía el artículo primero del Proyecto; para lo demás ya no hubo tiempo, antes triunfó Casa Mata. El nuevo exordio señalaba la improcedencia de la Constitución de Cádiz en estas tierras aquen de los mares, toda vez que había una gran desproporción de representantes peninsulares y americanos a las Cortes Constituyentes; que México como nación libre tenía el derecho de promulgar su propia carta magna; además, hacía la apología de Iturbide y señala el carácter provisional del Reglamento, en tanto se aprobaba la constitución definitiva.

Veamos ahora el contenido del Proyecto de Marras

1. Como ya señalamos, quedaba abolida — abrogada — la Constitución española; sin embargo, la legislación ordinaria promulgada hasta antes del 24 de febrero de 1821 quedaba en vigor, para lo cual, se nombraría una comisión que precisara ello y propusiera los cambios oportunos.

2. Se ratificaba como religión oficial, con intolerancia de cualquier otra, a la católica, conservando los clérigos sus fueros y preeminencias, restableciendo las órdenes de jesuitas y hospitalarios.

3. Se confirmaba como forma de gobierno el monárquico constitucional, representativo y hereditario, sobre la base de un Estado

61 Alamán nos dice "por reiteradas excitaciones del emperador, procedió á ocuparse de formar un reglamento...", Cfr. Op.cit. p. 430.

62 Cuando don José María Covarrubias planteó esta misma cuestión, don Toribio González, que presidía en ausencia del presidente, ya que era el primer vicepresidente, y coautor del Proyecto que se estaba discutiendo, le contestó diciendo que no se derogaba - abrogaba - la Constitución española, pues lo que de bueno y conveniente tiene para el Imperio Mexicano, es reproducido en el Proyecto de Reglamento en consideración y por lo inmenso de la empresa no era posible revisar toda la legislación secundaria, la cual se daba por buena. 
libre, independiente y soberano, unitario, con el nombre de Imperio Mexicano.

4. Se señala como mexicanos a todos los habitantes del Imperio que hayan reconocido la Independencia y los vecinos que con posterioridad se avecinen, con aprobación del gobierno y juren fidelidad al emperador y las leyes; en consecuencia, a los extranjeros que hayan prestado servicios al Imperio, el emperador, oyendo al Consejo de Estado e informando al ministro de Relaciones y al ayuntamiento correspondiente, podría otorgarles el "derecho de sufragio", la llamada "carta de naturaleza".

5. Se establecía como finalidad del gobierno la conservación, tranquilidad y prosperidad del Estado y sus individuos, garantizando los derechos de libertad, propiedad, seguridad e igualdad legal y exigiendo el cumplimiento de los deberes recíprocos.

6. En cuanto a los derechos fundamentales, intenta formular una especie de reglamentación, pero de una manera bastante desordenada; así habla de la inviolabilidad del domicilio, la libertad personal, la propiedad y la expropiación, que se garantizaba la deuda pública, se establecía la proporcionalidad de las contribuciones, la igualdad de los individuos para obtener cargos públicos, las libertades de pensamiento y expresión, la censura civil y eclesiástica en cuestiones religiosas, legalidad y garantías jurisdiccionales, las fuerzas armadas y el servicio militar.

7. Establece la división de poderes, indicando que no se podían reunir dos de ellos en una misma persona o corporación. Para ello, dispuso:

a) El Poder Legislativo, lo ejercería, mientras tanto, la Junta Nacional Instituyente, reproduciendo las Bases Orgánicas que se le habían dado y otorgándoles inmunidad parlamentaria a sus miembros. Se señaló que un futuro congreso asumiría dicho poder, para lo cual se expedirían sendas leyes de convocatoria y orgánica.

b) El Poder Ejecutivo, correspondía al emperador, siendo su persona sagrada e inviolable, se establecen sus obligaciones y prohibiciones. Se auxiliaba de cuatro ministerios (ya no se hablaba de secretarías): del Interior y de Relaciones Exteriores (que antes se llamaba de Relaciones Exteriores e Interiores), Justicia y Negocios Eclesiásticos, Hacienda y Guerra y Marina, cuyos titulares eran los responsables 
de los actos de gobierno y eran nombrados libremente por el emperador. Se les encomendaba especialmente el cuidado y atención de los establecimientos de instrucción y moral pública.

Se preveía la existencia de una Regencia, integrada de uno a tres individuos, y sus suplentes, nombrados en secreto por el emperador, para el caso de su muerte o incapacidad física o moral. El príncipe heredero presidirá dicha Regencia, sin voto si fuera menor de 18 años, pues a partir de esa edad ocuparía el Trono (el emperador menor de edad no podrá casarse ni salir del Imperio sin autorización del Legislativo).

Continuaba el Consejo de Estado en los términos que lo había creado el Congreso Constituyente, dándole además, las facultades de presentar ternas para plazas de judicatura y presentación de beneficios eclesiásticos y obispados (los obispos serían consejeros honorarios).

c) El Poder Judicial ordinario se integraba por alcaldes, jueces de letras, audiencias territoriales y un Supremo Tribunal de Justicia (para ser juez o magistrado se tenía que ser ciudadano del Imperio, mayor de 30 años, casado o viudo, no haber sido condenado por delito alguno y gozar de buena reputación, luces e integridad para administrar justicia).

Subsistían los fueros militar y eclesiástico, tanto para lo civil como para lo criminal, además de los tribunales especializados de minería y Hacienda, el Consulado exclusivamente para conciliación y arbitraje voluntario.

No podía haber más de tres instancias, con dos conformes de toda conformidad causaban estado y se establecía el recurso de nulidad (casación). La conciliación previa era obligatoria tanto en materia civil como criminal. Todo ello se regía conforme al Reglamento procesal gaditano del 9 de octubre de 1812.

d) En cuanto a los gobiernos provinciales y municipales, de disponía: que en cada provincia habrá un jefe superior político, nombrado por el emperador, conjugando el mando político y militar de la provincia mientras persistiera el amago de enemigos exteriores, el cual acordaba directamente con el ministro del Interior; en los puertos de mar que no fueran capitales de provincia habría un jefe político subalterno. En los ayuntamientos, el alcalde 
primero sería nombrado por el jefe político. Subsistirían las diputaciones provinciales y ayuntamientos electos popularmente, conforme la legislación de Cádiz y con las facultades que determinaba la misma legislación.

Los intendentes de provincia serían exclusivamente autoridades hacendarias en su correspondiente provincia y suplirían al jefe superior político en sus ausencias.

Habiendo sido un proyecto que no pasó de su aprobación en lo general y por supuesto no habiendo entrado nunca en vigor, consideramos que no merece mayor detenimiento en su estudio y consideración.

\section{EL FIN DE ITURBIDE}

Como ya hemos mencionado, en los primeros días de diciembre de 1822, López de Santa Anna, en unión de algunos antiguos insurgentes como Guadalupe Victoria, Vicente Guerrero y Nicolás Bravo, se levantaron en armas, según el Plan de Veracruz, con el fin de instaurar la república en México; para ello, Iturbide comisionó a José Antonio de Echávarri para someter a Santa Anna, así, después de sitiarlo infructuosamente en el puerto de Veracruz, prefirió proclamar el 1 de febrero de 1823 el Plan o Acta de Casa Mata, según Alamán, ${ }^{63}$ a iniciativa de los masones, para que de esta forma concluyeran las hostilidades entre ambos jefes militares.

Pensamos que el éxito del Acta de Casa Mata, radicó en que de inicio no fue expresamente contraria al emperador, ${ }^{64}$ ni en favor de la República, sino que ante "los peligros que amenazan a la patria por la falta de representación nacional, único baluarte que sostiene la libertad civil" por ello, se acordó "a la mayor posible brevedad" instalar un nuevo Congreso, para lo cual, se podría reelegir a aquellos diputados cesados por Iturbide el pasado 31 de octubre. Para Jaime E. Rodríguez O. ${ }^{65}$ señala “El Plan de Casa Mata

63 Op. cit., p. 448.

64 En más, el artículo 11 decía "El ejército nunca atentará contra la persona del emperador".

65 Cfr. "Las cortes mexicanas y el Congreso Constituyente", en Virginia Gueda (coord.), La Independencia de México y el proceso autonomista novohispano 1808-1824, México, UNAM-Instituto Mora, 2001, p. 294. 
obtuvo el apoyo de las provincias porque incluía una cláusula que concedía autoridad local a las diputaciones provinciales".

De esta forma, se ordenaba poner copia del Acta en manos del emperador, quien evidentemente no se conformó con ella, enviando tropa a enfrentar a los alzados seguidores de Santa Anna, y además de ello, reaccionó de manera más razonable al mandar una comisión integrada por el general Pedro Celestino Negrete, el canónigo Mariano Nicolás Robles, el licenciado Juan José Espinosa de los Monteros, el licenciado Ramón Esteban Martínez de los Rios y el jefe político de Puebla, Carlos García, para dialogar con los firmantes del Acta, habiéndose reunido en la villa de Jalapa a partir del día 14 de febrero, luego se pasaron a Puebla y finalmente no concluyeron en nada.

Las pretensiones de los alzados era, como dijimos antes, convocar a un Congreso al tenor de la legislación española, que a sus soldados les pagara su salario la Tesorería del Imperio y que se estableciera una línea de demarcación para que, de esta forma, suspender las hostilidades y que no avanzara ninguno de los ejércitos: ellos, los alzados por Casa Mata, y los imperiales. Todo lo cual, el emperador posteriormente sometió a la consideración de la Junta Nacional.

Ante la cascada de adhesiones al Acta de Casa Mata ${ }^{66}$ y el desmoronamiento del gobierno imperial, el poderoso ministro de Relaciones, José Manuel de Herrera, al parecer fautor de todos los descalabros constitucionales de Iturbide, renunció el 21 de febrero de 1823; la capital nacional se puso en pie de guerra. El propio Iturbide se fue a Iztapaluca, previendo una confrontación armada de mayores dimensiones con el llamado "ejército restaurador del sistema constitucional ó libertador".

Finalmente, don Agustín, a propuesta del Consejo de Estado del 3 de marzo de 1823, con el aparente propósito de evitar mayor derramamiento de sangre, resolvió, al día siguiente, restablecer el antiguo Congreso, el que él había clausurado, sabiendo que estaban en la ciudad de México 109 diputados, y que de cumplir puntualmente las pretensiones de Casa Mata, particularmente lo relativo a convocar un nuevo constituyente, hubiesen llevado a la anarquía, ante la ausencia de un cuerpo legislativo deliberante, toda vez que la Junta Nacional Instituyente, estando totalmente deslegiti-

${ }^{66}$ El propio Pedro Celestino Negrete, hombre de confianza de Iturbide acabó adhiriéndose a Casa Mata. Además, la insinuación de un posible federalismo, convencía mucho a las provincias. Los republicanos veían una posible salida si triunfaba el Plan. Cfr. Ávila, op.cit., pp. 260 y ss. 
mada, había perdido - si alguna vez la tuvo - toda su credibilidad. El 6 de marzo de 1823 se celebró la última reunión de dicha Junta. El 10 de marzo, por la tarde, Iturbide salió de Iztapaluca con el fin de retornar a la capital nacional, pero prefirió establecerse en Tacubaya, cerca y lejos a la vez del centro de poder.

Dice el dicho que lo que mal comienza mal acaba, y así le sucedió a don Agustín de Iturbide y su fallido Imperio Mexicano, después de aquella sesión rocambolesca del Congreso Constituyente en la que inopinadamente se le nombró "emperador", ahora ni don Agustín ni sus epígonos tuvieron la capacidad de negociar el fin del conflicto con los seguidores del Plan de Casa Mata, que pedía precisamente lo que estaba discutiendo en ese momento la Junta Nacional Instituyente: la convocatoria a un nuevo congreso constituyente; no pedían la cabeza de Iturbide ni el fin del Imperio; pedían lo que ya se estaba haciendo. Pero, ni modo, así es la vida, y la falta de oficio político, o quizá el desánimo (entonces no se hablaba de depresión y mucho menos de personalidad bipolar) de Iturbide y los pocos amigos que le quedaban; o quizá no era más que una manera de reconocer elegantemente el propio fracaso, todas las provincias lo abandonaban; el caso es que el malogrado monarca iniciaba el camino del fin.

Así, el 7 de marzo de 1823, 58 diputados del antiguo Congreso Constituyente (curiosamente, la mayoría de ellos miembros de la Junta, ahora con otra cachucha) se reunieron declarando abiertas las sesiones (aunque reconocieron que no había quórum para dictar ninguna ley). Se invitó al emperador, quien se presentó con el príncipe heredero, los ministros y el Consejo de Estado, se disculpó ligeramente de haber clausurado el Congreso, propuso no hubieran recriminaciones, cargos ni culpas, sino más bien que se considerara aquel día como el de la feliz reconciliación, hizo promesa de respetar la voluntad general, propuso se pagase los haberes de los alzados con cargo a la Tesorería, según lo pactado, y se expidiese una ley de amnistía. El vicepresidente del Congreso Constituyente en funciones, José María Becerra, contestó con cortesía pero con toda la frialdad del caso. Para ese momento, don Agustín de Iturbide era un hombre acabado.

Así, el 19 de marzo de 1823, don Agustín de Iturbide, emperador de México entregó a su compadre Manuel Gómez Navarrete, un ocurso escrito de su puño y letra, dirigido al Congreso, abdicando al Trono imperial y poniéndose a las órdenes del mismo Congreso, aunque siguió utilizando el título monárquico varios días más. Dicho escrito llegó ese mismo día 
por la noche al Congreso, éste no lo recibió oficialmente sino hasta el día siguiente. Finalmente, el cesante emperador, el 27 del mismo mes, notificó al Congreso su salida de Tacubaya y pedía perdón por si hubiera cometido algún acto de despotismo. ${ }^{67}$

El 30 de marzo de 1823, el Congreso nombró un triunvirato, con el nombre de Supremo Poder Ejecutivo, integrado por Nicolás Bravo, Guadalupe Victoria y Pedro Celestino Negrete, como titulares, y Mariano Michelena, Miguel Domínguez y Vicente Guerrero como suplentes, con el objeto de encargarse interinamente de dicho poder. El 5 de abril siguiente se nombró una comisión para analizar la abdicación de Iturbide, integrada por Becerra, Osores, Espínoza, Horbegoso, Zavala, Muzquiz, Castro y Herrera, la cual propuso, ese mismo día, anular la coronación del susodicho "como obra de la violencia y de la fuerza, y de derecho nulo", también anulaba la sucesión hereditaria de los títulos emanados de la coronación, lo cual fue discutido el día 7 y aprobado por el pleno al día siguiente; además, se le exiliaba, se le daba tratamiento de excelencia y una pensión vitalicia de veinticinco mil pesos anuales. Obviamente se declararon insubsistentes el Plan de Iguala y los Tratados de Córdoba. Todavía, a principios de octubre de 1823 , hubo un intento de levantamiento en favor de Iturbide, que por supuesto, no tuvo ningún éxito.

Llevábamos dos años y medio como nación independiente y no nos poníamos de acuerdo en lo que queríamos ser, en ello ya habíamos derramado sangre de compatriotas y estábamos peor que al principio. Parecería como si Agustín de Iturbide hubiera dado la clave para manejar el país, por lo menos en los siguientes cincuenta años: las inconsistencias, las bravuconadas y los dobles discursos, todo lo cual fue secundado por los hombres públicos - los publicistas - de aquel entonces; pareciera que el diálogo político se llevara a cabo conforme al método Ollendorf. ${ }^{68}$ Era el primer acto del gran drama nacional que viviría nuestro país en ese calamitoso, aunque apasionante, siglo XIX.

67 Ibidem, p. 271.

68 Era un método para aprender lenguas extranjeras, un tanto cuanto peculiar, propuesto por el profesor alemán Heinrich Gottofried Ollendorff, en el siglo XIX, según el cual cada estudiante expresaba en el lenguaje que estaba aprendiendo, una frase breve la cual era respondida por otro estudiante por otra frase que no tenía nada que ver con la primera, produciéndose diálogos absurdos e inconexos. 


\section{UN NUEVO AMANECER}

Cuando Iturbide se había negado a convocar un nuevo congreso constituyente, el 10 de marzo de 1823, la Diputación Provincial de Puebla convocó a las demás provincias a enviar a la capital Angelopolitana a dos delegados, con el propósito de constituir una convención que se denominó Junta de Puebla, con el fin de formar un nuevo gobierno nacional, convención que tuvo una buena participación de delegados provinciales; sin embargo, en el entretanto, llegó la noticia de la resignación de don Agustín, por lo cual dicha Junta no tuvo más remedio que reconocer el antiguo Congreso Constituyente, pero sólo con el objeto de que convocara un nuevo constituyente. ${ }^{69}$ Para esto, el llamado "ejército liberador", o sea el surgido de Casa Mata, entró en la ciudad de México el día 27.

El problema era, como señalamos antes, que el Congreso recién reinstalado no alcanzaba el quórum legal para funcionar, lo único que lograron en estos primeros momentos es declararse formalmente instalados, pero sin capacidad de tomar resolución alguna, ello se consiguió hasta el 29 del mismo mes de marzo. En efecto, según el acta correspondiente a ese día, ${ }^{70}$ había 102 diputados presentes ${ }^{71}$ y componiéndose el Congreso, para esos precisos momentos, de 182 integrantes, bastaba la presencia de por lo menos 92 legisladores; por lo tanto, la magna asamblea declaró: "se halla reunido en su mayoría; en plena y absoluta libertad de deliberar, y por consiguiente en estado de continuar sus sesiones"; como dijo el maestro de Salamanca, fray Luis de León: deciebamus hesterna die.

En la misma sesión se acordó "Se declara haber cesado el poder ejecutivo de México existente hasta ahora desde el 19 de mayo del año anterior", o sea que ni siquiera quisieron mentar el nombre de Agustín de Iturbide y mucho menos el cargo que ellos mismos le dieron y en multitud de ocasiones ratificaron de manera tácita con la forma como lo trataron: "emperador". Asimismo, se resolvió que el ejercicio del poder ejecutivo se depositaría en individuos (ojo, plural) nombrados por el Congreso, para lo cual se formaría una comisión para proponer la denominación, número de integrantes,

70 Cfr. Diario de la sesiones del Congreso Constituyente de México, cit., T.IV pp. 85-87.

71 Aunque el diputado José Ignacio Espinoso señaló que eran 103, nosotros sólo contamos 102. Ibidem, p. 88. 
tratamiento y demás detalles para el desempeño de las funciones de este colectivo. Dicha comisión se integró por los diputados Francisco Tarrazo, Valentín Gómez Farías, José María Fagoaga, López de la Plata y Bonifacio Fernández de Córdova. También se creó otra comisión para redactar un manifiesto dirigido a la Nación expresando que el Congreso había recuperado sus funciones y estaba trabajando con total libertad, integrada por Carlos María de Bustamante, Sánchez de Tagle y Larreinaga.

En ese momento, no cabe duda, el Congreso Constituyente había dado su voto por la república.

Como señalamos antes, el 30 de marzo de 1823, se presentó el dictamen de la comisión ad-hoc, en el cual se proponían cinco puntos: el poder ejecutivo lo ejercerá provisionalmente una Junta Gubernativa, la que se compondrá de tres individuos, que se alternarán mensualmente en la presidencia, por el orden de su nombramiento; tendrá tratamiento de alteza y sus integrantes de excelencia; estos no podrán ser miembros del Congreso y su funcionamiento se regirá por el último reglamento que se presentó al Congreso para la antigua Regencia.

En cuanto al nombre, no estuvieron de acuerdo, ya que no reflejaba lo que se pretendía fuera (ejecutivo) y después de varias propuestas se acordó que se llamara Supremo Poder Ejecutivo; don Carlos Bustamante propuso se nombrasen suplentes, pero no se aceptó; tampoco se aceptó lo del tratamiento de alteza, sólo que a los mencionados integrantes, en contestaciones oficiales, se les diera tratamiento de excelencia. Aunque se aprobó que los miembros de dicho triunvirato no fuesen, por razones obvias, miembros del Congreso, se pidió excluir de tal prohibición a don Guadalupe Victoria, pero no se vio necesaria tal dispensa, ya que don Guadalupe nunca había sido reconocido como diputado, por lo tanto, se acordó estaba en aptitud de ser nombrado miembro del Poder Ejecutivo (con lo cual se aseguraba su designación). Todos los demás extremos del dictamen fueron aprobados tal cual.

De esta forma, al día siguiente, 31 de marzo de 1823, a las once y media de la mañana se suspendió la sesión pública del Congreso para dar paso a la sesión secreta, con el fin de resolver el tema de los integrantes del Supremo Poder Ejecutivo. Se volvió a abrir la sesión pública a las tres y media de la tarde del mismo día, con el objeto de dar a conocer los nombres del triunvirato llamado a ejercer dicho Poder, habiendo resultado electos, como señalamos antes, los generales Pedro Celestino Negrete, Guadalupe 
Victoria y Nicolás Bravo. ${ }^{72}$ Ese mismo día el general Negrete rechazó el nombramiento, pero el Congreso insistió y tuvo que aceptar; sin embargo, por no hallarse presentes en la capital los otros dos integrantes, el propio Negrete pidió se nombrasen dos suplentes, lo cual se reservó al día siguiente para acordarse; en consecuencia, compareció don Pedro Celestino a rendir el juramento de estilo y se levantó la sesión a las diez de la noche. De esta forma, según lo previsto, en la sesión del 1o. de abril, se nombraron los dos suplentes: Mariano Michelena y Miguel Domínguez, quienes rindieron el juramento en la misma sesión. Más adelante, por necesidades de la gran movilidad que tenían los integrantes del gobierno, en su calidad de jefes militares, se tuvo que nombrar un tercer suplente, que recayó en Vicente Guerrero.

\section{PARA DESPEDIR A DON Agustín}

Hemos pasado revista al desarrollo constitucional del primer año y medio de vida independiente de nuestro país, 18 intensísimos meses de vida institucional que más parece un caos que la construcción de un nuevo Estado, o a lo mejor ese desconcierto es parte de esta especie de adolescencia fundacional, el caso es que la falta de experiencia de la mayoría de los publicistas - como se decía entonces - mexicanos se vería reflejada en este batiburrillo.

Hemos visto desfilar ante nuestros ojos enormes gestos tanto de grandeza como de miseria humanas, la más alta vocación de servicio junto con la mezquindad de nuestros primeros hombres públicos, lo cual no va a ser sino el incoar el himno épico que va a constituir nuestra historia constitucional durante los siguientes cien años. Nos guste o no, somos descendientes de aquellos prohombres que empezaron a construir el México contemporáneo y por ello mismo sus causahabientes. No nos debemos asustar de las similitudes de lo que hicieron entonces y lo que hacemos ahora, pues como dice el dicho popular, "quien lo hereda no lo hurta".

Desde el punto de vista de la historia del derecho, lo primero que nos llama la atención es lo poco estudiado de este primer momento del México Independiente. Hablando coloquialmente esta etapa de nuestra historia tiene "mala suerte", quizá porque está marcada principalísimamente por la

72 Jaime E. Rodríguez O. señala "Al designar generales..., el Congreso restaurado trataba de controlar a los militares...; sin embargo, el gobierno nacional no pudo dominar por completo a las fuerzas armadas", op. cit., p. 298. 
presencia y actuación de don Agustín de Iturbide, personaje que, incuestionablemente, no goza de la mejor opinión en el "imaginario colectivo". Lo malo es que ha arrastrado en su infortunio a muchos otros coetáneos suyos, quienes no han sido correctamente justipreciados en su actuar público. El amable lector encontrará en estas páginas muchos temas que esperan ser trabajados desde la perspectiva de la historia del derecho constitucional, ojalá pronto lo sean.

Una Nueva España que no acaba de morir y un México que no acaba de nacer es lo que hemos visto en las páginas anteriores, un doloroso tránsito institucional entre un régimen absolutista, el ancien régime, a un Estado liberal y democrático de derecho; por eso nos desconcertamos. También por ello no debemos ser tan duros e inflexibles para juzgar estos primeros meses de nuestra etapa independiente. De una cosa sí estamos seguros: la buena fe de nuestros primeros publicistas, estamos convencidos que todos ellos querían el mejor país, con mucho o poco talento, con mayor o menor preparación, con más o menos experiencia, equivocados o atinados, pero eso sí, todos buscaban lo que para ellos era lo mejor para México.

\section{XVI.LA NACIÓN FRENTE AL SEGUNDO OBSTÁCULO}

Tratando de hacer un apretado resumen de lo anotado párrafos arriba, después de las aventuras golpistas de don Agustín de Iturbide en su papel de emperador de México, cuando clausuró el Congreso Constituyente el 31 de octubre de 1822, erigió una Junta Nacional Instituyente y al triunfo, en los hechos, del levantamiento de Casa Mata, no tuvo más remedio el frustrado monarca que restablecer, por Decreto del 3 de marzo de 1823, el Constituyente, lo que se llevó a cabo el día 7 del mismo mes; de tal surte que el desprestigio del soberano mexicano era tal, y yo creo que hundido en la depresión, que no tuvo otra salida que abdicar al Trono imperial el día 19 de marzo. La reacción oficial del Congreso, como ya vimos, tuvo que esperar a que se formara el quórum legal, lo que se consiguió hasta el 29 de marzo, y con tan mala suerte que ni siquiera le aceptaron tal renuncia, al considerar que su designación había sido nula de pleno derecho, producto de una vis moralis; y por lo tanto, no procedía la abdicación, como se acordó el 8 de abril, junto con lo correlativo del Plan de Iguala y Tratados de Córdoba. Ello no fue obstáculo para 
que desde el 30 de marzo se nombrara un triunvirato que se hiciera cargo del Poder Ejecutivo.

Dice Reynaldo Sordo Cedeño ${ }^{73}$ que el período que corrió entre el 7 al 23 de mayo de 1823, existió un vacío de poder, Iturbide dejó la ciudad de México y se fue a Tacubaya el 11 del mismo mes y convergieron en Puebla los principales jefes del movimiento de Casa Mata, lo que sin duda facilitó el desarrollo de los movimientos autonomistas en las provincias.

Parece que la decisión republicana estaba tomada y ahora el país se enfrentaba a otra decisión no menos importante y trascendente: constituirnos como federación o escoger el centralismo. Así como, después del triunfo de Casa Mata, las provincias reclamaban mayor autonomía, mientras que no faltaba quien pedía un gobierno central fuerte, capaz de enfrentar los múltiples problemas que la nación encaraba día con día.

En efecto, nos informa Lucas Alamán: ${ }^{74}$

Los partidos despues del triunfo obtenido sobre Iturbide, habian mudado de composicion y se agitaban con mas fuerza que nunca. Los republicanos se dividieron entre centralistas y federales: formaban el primero los masones y los antiguos monarquistas, por lo que se daba á esta fraccion el nombre de borbonistas y á ella pertenecia el gobierno y el congreso restablecido: á los federalistas se unieron los iturbidistas... y por esta causa vinieron á incorporarse en el partido liberal mas exagerado.

Y continúa señalando: "Cada partido tenia su periodico, habiéndose restablecido el Sol, no ya para defender la monarquia sino para sostener la república central y al gobierno y congreso que la promovian . Los federalistas comenzaron a á publicar el Archivista, que tomó despues el título de la «Aguila mejicana»".

Es importante referirnos ahora a la última institución que quedaba del Imperio de Iturbide, el Consejo de Estado (si entendemos que el Congreso Constituyente era una institución anterior a la adopción del régimen imperial). En la sesión del Congreso del 18 de abril de $1823,{ }^{75}$ se presentó un dictamen

73 "El Congreso Nacional : de la autonomía de las provincias al compromiso federal" en Establecimiento del Federalismo en México, 1821-1827, Coord. Josefina Zoraida Vázquez, México, El Colegio de México, 2003, p. 120.

74 Op. cit., t. V p. 481.

75 Cfr. Diario de las sesiones del Congreso Constituyente de México, cit., t. IV pp. 303 y ss. 
de la Comisión de Puntos Constitucionales referente a la propuesta de los diputados Nájera y Lombardo sobre la supresión de dicho Consejo, y en vista de la opinión del Ejecutivo que consideraba que ello no era oportuno, pues el Gobierno requería "tener un cuerpo con que consultar en los negocios graves y árduos"; y en virtud de que su costo no era elevado, pidieron continuara dicha corporación. Así, después de una muy intensa discusión, el Congreso decidió no aceptar el dictamen y acordar la disolución del Consejo de Estado, pues como señaló Carlos María de Bustamante, ${ }^{76}$ recogiendo además la opinión de otros constituyentes, era una "corporación exótica en un gobierno liberal" además que "bastantes méritos ha[bía] dado para ser demolid[a]"; posteriormente (29 de noviembre) se comunicó a los miembros del Consejo que el Congreso disponía retornaran a los anteriores puestos que tenían antes de ser designados y que se les cubriera la mitad del sueldo que hubieran percibido hasta ese mes.

Para esto, las provincias empezaban a pedir que el Congreso convocara a un nuevo Constituyente en el que se salvaran las objeciones formuladas a la asamblea reunida el 24 de febrero de 1822, en lo relativo a la desproporción en la representación, que primero había impulsado Iturbide y luego él mismo lo había criticado.

Para ello, a petición de los diputados Gómez Farías y Múzquiz, el de mayo de 1823, se nombró en el seno del Congreso una comisión especial para dictaminar sobre la convocatoria a un nuevo congreso y formulara un proyecto de Constitución, integrada por Mariano Herrera, Javier Bustamante, Carlos Bustamante, Francisco Manuel Sánchez de Tagle, Toribio González, Beltranena y el propio Valentín Gómez Farías. ${ }^{77}$ Esta Comisión, a excepción de Gómez Farías, propuso que el Congreso siguiera funcionando, que en su seno se formase una comisión que redactase el proyecto de constitución, y que la misma Comisión propusiera si para su aprobación final se convocara un nuevo constituyente o fuera el propio Congreso en funciones quien lo llevara a cabo. Dicho dictamen fue aprobado por el Pleno.

Las provincias no estaban de acuerdo, consideraban que el Congreso en funciones, como señalamos antes, no respondía a una representación proporcional y por ello pedían un nuevo Constituyente que respondiera a dicho principio, según lo preveía la Constitución española.

76 Citado por Manuel Ferrer Muñoz, La formación de un Estado nacional en México (El Imperio y la República), México, UNAM, 1995, p. 247.

77 Ibidem, p. 137. 
La primera reacción provincial vino de Yucatán. Señala Jaime E. Rodríguez O. ${ }^{78}$ que el 19 de abril se reunieron los miembros de la Diputación Provincial y del Ayuntamiento de Mérida, en lo que se denominó Junta Provisional Administrativa, la que acordó, el día 25, reconocer a los poderes nacionales, bajo las condiciones de que se convocara un nuevo Constituyente y se comprometieran a no intervenir en los asuntos internos de Yucatán; para ello, empezó a organizarse sin esperar las decisiones del centro. ${ }^{79}$ José Barragán, relata esta historia de manera diferente, y más detallada, lo cual no preocupa para los efectos de este trabajo, quien esté interesado en ello puede acudir a los escritos de ambos autores y tomar su decisión; ahora lo único que nos ocupa es lo que Barragán señala: "La Junta evidentemente rompía el orden legal consagrado. Nosotros pensamos que existe algo más en el trasfondo: al menos históricamente, dicha Junta marca el inicio de la autodeterminación soberana y libre del Estado de Yucatán". ${ }^{80}$

Más adelante, la Diputación Provincial de Guadalajara, el 9 de mayo de 1823, en virtud de que se había reconocido la autoridad del Constituyente reinstalado, únicamente para que convocara uno nuevo, y como esto no era ya posible, procedió a desconocerlo, y tres días después, en unión con el Ayuntamiento de la ciudad capital de la provincia, decidieron apoyar el federalismo, y reiteraron que, mientras tanto, no obedecerían al Congreso ni al Supremo Poder Ejecutivo; y de manera similar a Yucatán, acordaron se obedecería a una junta integrada por la Diputación de la Provincia de Jalisco como se empezaba a llamar, junto con tres miembros del Cabildo de Guadalajara. Todas estas resoluciones se comunicarían a las demás diputaciones provinciales, instándolas a formar una federación; de tal suerte, este fue el primer pronunciamiento oficial en favor de la Federación.

El 14 de mayo de 1823, se dio a conocer que los diputados Servando Teresa de Mier, José del Valle, José María Jiménez, Juan de Dios Mayorga, Francisco María Lombardo, José Mariano Marín, Lorenzo de Zavala y José María Bocanegra, a instancias del padre Mier, habían trabajado en secreto un

78 Cfr. "Las cortes mexicanas y el congreso constituyente", op. cit., pp. 209 y 210.

79 Junta Provisional Administrativa para hacer observar las leyes, guardar los derechos de los ciudadanos y de dirigir la administración pública, funciones absolutamente necesarias para mantener el orden y tranquilidad general, y evitar las funestas consecuencias de la anarquía.

${ }^{80}$ Cfr. Introducción al federalismo (La formación de los poderes en 1824), reimpresión, Guadalajara, Universidad de Guadalajara, 1994, p. 137. Personalmente nos parece más acertado lo apuntado por este autor. 
proyecto de constitución, del cual hablaremos más adelante, con el nombre de Plan de la constitución política de la nación mexicana sobre las bases de la República federativa.

El sábado 17 de mayo, por la tarde, el secretario de Relaciones Interiores, don Lucas Alamán, se presentó en una sesión extraordinaria para informar los sucesos de Guadalajara, al día siguiente, domingo 18, se volvió a presentar para narrar lo que había pasado en Yucatán y el temor que se desmoronara la nación. Para el 21 de mayo de 1823, ${ }^{81}$ la Comisión Especial nombrada para Proponer las Medidas Conducentes y Propias á Fin de Evitar los Males que Amenazan a la Patria, propuso convocar un nuevo Congreso Constituyente, lo cual fue aprobado por una mayoría de 71 votos contra 33 (sobre todo, estos últimos diputados de la provincia de México, el sempiterno centralismo chilango).

En dicho Decreto, el Congreso dispuso, además, que se ocuparía, en tanto se reuniera al nuevo Constituyente, en la organización de la Hacienda, del Ejército y de la administración de justicia; igualmente, que de inmediato se imprima y circule el Proyecto de Bases de República Federativa (después se añadió la precisión "Por la Comisión de Constitución del Congreso" y se cambió lo de "república federativa" por "Nación Mexicana"), antes mencionado, y, a propuesta del diputado José María Fagoaga, se ordenaba al Ejecutivo tomara todas las medidas y precauciones para restablecer la tranquilidad pública en Guadalajara, "prefiriendo las medidas de persuasión y convencimiento antes de rigor y uso de las armas". El Proyecto de Bases se leyó en el Congreso el 28 del mismo mes.

Al día siguiente, se nombró una comisión para presentar el proyecto de convocatoria, integrada por los diputados Francisco García, Carlos María de Bustamante, Prisciliano Sánchez, Bonifacio Fernández, Melchor Múzquiz, Cabrera y José C. del Valle, quienes presentaron su propuesta el 11 de junio de 1823, mismo día que se empezó a discutir (incluso en el día domingo) y se concluyó el 17. El lunes 23 de junio de 1823, el gobierno publicó solemnemente el bando de convocatoria al Segundo Congreso Constituyente. Las elecciones se llevaron a cabo los días 3 y 17 de agosto y 6 de septiembre de 1823. Trátase de un ordenamiento largo, complicado y en ocasiones detallista, con 102

81 Cfr. Mateos, Juan A., Historia parlamentaria de los congresos mexicanos, edición facsimilar (tomada de la de J.F. Jens, México, 1878) México, Cámara de DiputadosMiguel Ángel Porrúa, 1977, t. II, p. 373. 
artículos, inspirado en gran medida en el ordenamiento electoral gaditano, lo cual se explica por la carencia de una Constitución.

Como señalamos antes, el nuevo constituyente se formaría sobre la base del número de pobladores, correspondiendo un diputado por cada 50,000 habitantes o fracción que supere los 25,000; las provincias que no lleguen a los 50,000 habitantes, de cualquier forma tendrían derecho a un diputado. Las provincias eran: México, Querétaro, Guadalajara, Puebla, Veracruz, Yucatán, Tabasco, Oaxaca, Guanajuato, Valladolid, San Luis Potosí, Zacatecas, Tlaxcala, Nuevo Reino de León, Nuevo Santander, Coahuila, Tejas, Durango, Sonora, Sinaloa, Nuevo México, Antigua California y Nueva California; posteriormente, en la sesión del 14 de julio de 1823, se dividió Durango, la antigua Nueva Vizcaya, habiendo surgido Durango y Chihuahua. Se elegirían también suplentes, los que corresponderían a la tercera parte de los propietarios y en aquellas provincias que sólo tuvieran un propietario también tendrían un suplente. Tendrían derecho a votar todos los varones mayores de 18 años. [Fray] Servando (que ya no era fraile, pero así se le conoce comúnmente) propuso fuera bicameral, pero finalmente no fue aprobado.

Siguiendo el modelo gaditano, como señalamos antes, las elecciones se harían en tres instancias, a través de juntas primarias (correspondiendo a los municipios o similares), en donde se elegirían los electores primeros (uno por cada 100 vecinos o 500 habitantes - no sé lo que quiera decir esa distinción - ; si la fracción superara la mitad, se elegiría otro; si no llegare a esa cantidad de vecinos o habitantes, en un sólo municipio, también elegiría uno). Los electores primarios de un partido integrarían las juntas electorales secundarias o de partido; por cada 20 electores primarios se elegiría uno secundario; como en el caso anterior, si la fracción supera los 30 se elegiría otro más y si no llegaran a 20 electores primarios en todo el partido, también se elegiría uno. Las juntas electorales de provincia se integrarían con todos los electores secundarios de la provincia (que tenían que ser por lo menos cinco) cuya misión sería elegir a el o los diputados que representaran a la provincia en el Congreso Constituyente; para ser electo diputado se necesitaría mayoría absoluta de votos [es decir la mitad más uno] de los electores secundarios) y si no se alcanzare, se llevaría a cabo una segunda vuelta con los dos que hubieran tenido mayor votación, y en caso de empate, decidiría la suerte. Después de elegidos los propietarios se elegirían los suplentes. 
Los requisitos para ser diputado eran: ser ciudadano en pleno goce de sus derechos, mayor de 25 años, originario de la provincia que iba a representar o avecinado en ella por lo menos durante siete años (los extranjeros naturalizados no podía ser electos), laico o eclesiástico secular. Un requerimiento curioso era que si el candidato pertenecía "á clases distinguidas"; es decir, gozare de fuero (por ejemplo, eclesiásticos o militares) o fueran constituyentes en funciones, necesitaría una votación de por lo menos dos terceras partes de electores (dice C.M. de Bustamante: "y de este modo se evite el que se llene el Congreso de clérigos y se torne en Concilio"). ${ }^{82}$ El Congreso resolvió que los que entonces fueran diputados constituyentes no lo podrían ser para el Segundo Constituyente; sin embargo, el Ejecutivo, en la convocatoria, omitió esta restricción, por considerar que se limitaba la libertad de las provincias. Al día siguiente de haber elegido diputados constituyentes, se renovarían las diputaciones provinciales en su totalidad.

El nuevo Constituyente se tendría que reunir el 31 de octubre, o antes si el número de diputados fuese bastante; el quórum se formaría con la mitad más uno de los diputados, que se calcularon en 115, aunque para aprobar alguna norma constitucional se requería la presencia de por lo menos dos terceras partes.

Dice Felipe Tena Ramírez ${ }^{83}$ que el 12 de junio, el Congreso emitió el "Voto del Congreso" que lo hacía ya no con carácter de constituyente, pues ya lo había dejado de ser, para convertirse en sólo convocante, mediante el cual "se declaraba por el sistema federal"; pero no señala fuente. Por otro lado, José Barragán, en su libro El federalismo mexicano. Visión histórico constitucional $^{84}$ repite lo apuntado por Tena Ramírez, y en nota a pie de página cita su anterior libro Introducción al federalismo (La formación de los poderes en 1824) ${ }^{85}$ al que califica de "escueto e inexpresivo voto" sobre el que expresa "Posiblemente fue discutido y formulado durante sesión secreta" y luego lo reproduce, pero tampoco señala fuente. Sin embargo, revisando la Historia parlamentaria de Juan A. Mateos, no encontramos tal declaración en el acta

${ }^{82}$ Cfr. Diario... Editado en versión disco compacto por Josefina Zoraida Vázquez y Héctor Cuauhtémoc Hernández Silva, México, CIESAS-El Colegio de México-INAOE, 2003. "Diario de las ocurrencias principales de México", correspondiente al 13 de junio de 1823.

83 Cfr. Leyes fundamentales de México, 9a. ed. México, Porrúa, 1980, p. 147.

84 México, UNAM, 2007, p. 56.

${ }^{85}$ Op. cit., p. 174. 
de ese día ${ }^{86}$ Finalmente, diremos que un testigo de altísima calidad, por ser diputado constituyente en esa oportunidad, e historiador, don Carlos María de Bustamante en su inmortal, ya citado, Diario histórico de México 1822$1848,{ }^{87}$ no consigna tal resolutivo. ${ }^{88}$

Manuel Calvillo ${ }^{89}$ da más luz al respecto, después de mencionar que ni el acta de la sesión del 12 de junio, ni Bustamante ni Zavala hacen referencia a dicha disposición, señala que Bocanegra es quien se refiere a ella. El problema está, en nuestra modesta opinión, en que no fue una declaración paladina y clara del Congreso en favor del federalismo, como lo demuestra el hecho de que no consta en la mayoría de las fuentes consultadas, sino, como lo señala el propio Calvillo, con base en lo recogido por J. M. Bocanegra, fue una orden que emitió el Congreso en estos términos: "que el gobierno puede proceder a decir a las provincias estar el voto de su soberanía por el sistema de república federada". Para todo caso, y de una manera indirecta, el voto federalista del Congreso se dio en la sesión antes citada del 21 de mayo de 1823, cuando se aprobó el dictamen de la Comisión Especial para convocar un nuevo constituyente y en cuyo artículo tercero se dispuso: "Que se imprima y circule inmediatamente el Proyecto de Bases de la República Federativa".

Concluye Calvillo:

Al promulgar la convocatoria para el nuevo Congreso Constituyente, el 17 de junio, por más que no se imponga más limitaciones en los poderes de los diputados que el mantener las bases de religión, independencia y unión, el supuesto de la república federal está dado por los acontecimientos.

Otro tema era el Poder Judicial, durante el Imperio no se acabaron de poner de acuerdo sobre la integración del Supremo Tribunal de Justicia, sobre todo, por la forma de designación de sus integrantes. Para esto, el 20 de junio de 1823, el Congreso Constituyente, aprobó el Dictamen de la Comisión de Puntos Constitucionales "sobre nombramiento del Supremo Tribunal de Justicia", que a través de diez artículos disponía:

86 Op. cit., pp. 396-398.

87 Cfr. Correspondiente al día 12 de junio de 1823.

88 Es más, Bustamante nos cuenta que en la sesión del 25 de junio "El ministro de Justicia expuso que el gobierno, deseoso de que los males no sigan adelante, proponía al Congreso se adoptase una Acta Federal Provisional, entre ésta y las provincias".

89 P. 452. 
que se estableciera provisionalmente un Supremo Tribunal de Justicia "con las atribuciones que le señala la constitución —o sea la de Cádizy leyes vigentes", compuesta de trece ministros, integrando tres salas (la primera con 3 y la segunda y tercera con 5 ministros cada una), el primero designado lo presidiría con el título de "decano" (como en la Real Audiencia virreinal); éstos tendrían tratamiento de "señoría" y el Tribunal de "alteza". Además de un fiscal. La designación de estos togados la haría el Congreso, sobre la base de ternas que formulara el Supremo Poder Ejecutivo, el cual, además, formularía un proyecto de reglamento interior, para ser aprobado por el mismo Congreso. ${ }^{90}$ Finalmente nunca llegó a erigirse este Supremo Tribunal.

Regresemos a la situación que en ese preciso momento vivía nuestro país e iba a resultar determinante para su futuro, cuando se iba a tomar una de las decisiones más importantes, consistente en determinar la forma misma del Estado Mexicano: ¿república federal o centralista?; suscitándose una fuerza en favor del federalismo que ya va a ser imparable: movimiento que va a tener su punto de arranque con los acontecimientos de Guadalajara, que hemos comenzado a relatar párrafos atrás.

En efecto, el 16 de junio de 1823 se reunieron la Diputación Provincial, el jefe político superior, Luis de Quintanar (quien a pesar de haber sido enviado por Iturbide, finalmente se adhirió a las fuerzas progresistas de la provincia) y el Ayuntamiento de la ciudad capital, transformaron la antigua provincia de Guadalajara en el estado libre de Jalisco, por medio del Plan Provisional del Gobierno del Estado de Jalisco; el 21 de junio de 1823, el mismo jefe político, Luis Quintanar, publica el Manifiesto que hace la Diputación Provincial del Estado Libre de Jalisco, del derecho y conveniencia de su pronunciamiento en República Federada, el cual ha sido ampliamente estudiado por José Barragán Barragán, ${ }^{91} \mathrm{y}$ a cuya lectura remitimos a quien tenga mayor interés en el mismo, aunque es difícil de entender si no se conoce la historia de Jalisco.

El problema se suscitó más adelante, en virtud de que en la convocatoria para un nuevo constituyente antes referida, como dijimos antes, también se ordenaba a las provincias llamar a elecciones para renovar sus diputaciones provinciales, lo cual fue muy mal tomado por Guadalajara y Zacatecas,

90 Para conocer todas las peripecias legislativas para formar un Supremo Tribunal de Justicia. Véase Barragán, Introducción al ..., cit. pp. 234-263.

91 Op. cit., pp. 149 y ss. 
las que consideraron tal medida como una interferencia de las autoridades centrales en su régimen interior, lo que sólo a ellos correspondía decidir.

El gobierno nacional, en cumplimiento a lo dispuesto por el Congreso, que apuntamos antes, envió fuerza armada para sofocar la rebelión de esas provincias, al mando de dos de los integrantes del Supremo Poder Ejecutivo, los generales Negrete y Bravo, y estando a punto de estallar el conflicto bélico, se pudo resolver gracias al diálogo que se llevó a cabo en Lagos del 8 al 18 de agosto de 1823. Ambas provincias aceptaron convocar a elecciones, Guadalajara el 14 de septiembre y Zacatecas el 19 de octubre, pero no para diputaciones provinciales, según el modelo de Cádiz, sino para congresos locales, de corte federalista, como se había acordado antes, habiendo sido imitados posteriormente por Oaxaca y Yucatán.

A mayor abundamiento, el inefable Antonio López de Santa Anna, se había embarcado con su tropa en Veracruz, para desembarcar en Tampico y dirigirse a San Luis Potosí, en donde se declaró, el 5 de julio, "protector del sistema federal", y finalmente entró en conflicto con las autoridades locales, llegaron incluso a punto del conflicto armado, por lo cual, el gobierno nacional envió al brigadier Gabriel de Armijo al frente de una fuerza armada; sin embargo, como las demás provincias del centro del país le negaron el apoyo a Santa Anna, en la llamada Junta de Celaya, éste tuvo que abandonar sus pretensiones, se puso a las órdenes del gobierno y el 10 de julio abandonó San Luis Potosí, con el fin de responder judicialmente de sus acciones en la ciudad de México, dejando sus fuerzas expedicionarias resguardadas en la ciudad de Querétaro.

En efecto, el 1o. de julio de 1823, se reunieron en esa ciudad guanajuatense los jefes políticos de Michoacán, Querétaro, Guanajuato y San Luis Potosí, un representante de Armijo y otro de Santa Anna, con el objeto de resolver el conflicto creado por este último; dicha Junta reconoció al gobierno nacional y negó, como ya se señaló, el apoyo a don Antonio. La Junta de Celaya se disolvió el 11 de julio de $1823 .{ }^{92}$ Previamente, el día anterior por la noche, la Junta había llegado a esta conclusión: "La opinión de las cuatro provincias es que se constituya en República Federada, en los términos que el futuro congreso determine". ${ }^{93}$

A mayor abundamiento, en algunas provincias se mandató expresamente a sus diputados constituyentes a que se pronunciaran en favor del federalismo,

92 Rodríguez O., op. cit., p. 305.

93 Barragán, Introducción ..., cit., p. 146. 
como fue el caso de Yucatán, Michoacán, Zacatecas, Oaxaca y por supuesto Jalisco.

Para esto, el 1o. de julio de 1823, la Asamblea Nacional Constituyente reunida en la ciudad de Guatemala, había proclamado la Declaración de Independencia Absoluta de Centroamérica, creando las Provincias Unidas del Centro de América, asamblea a la cual se unieron, para el mes de septiembre, los representantes de Honduras, Nicaragua y Costa Rica, quienes, el 2 de octubre, ratificaron tal Declaración de Independencia; con lo cual perdíamos una buena porción de territorio, que en honor a la verdad nunca, particularmente en la época colonial, había sido nuestra. La provincia de Chiapas, que era parte de Guatemala, prefirió reincorporarse a México. Pero regresemos a la capital de la República Mexicana, en donde el Congreso Constituyente en sesión de 18 de octubre de 1823, después de detenido estudio por la "comisión especial nombrada para los asuntos de Goatemala", resolvió aceptar el "pronunciamiento de Independencia acordado en acta de 1o. de julio por el Congreso de Goatemala, (cuyos derechos respeta este de México) pueden retirarse los señores diputados de aquellas provincias"; y al día siguiente resolvió, como artículo 2o.: "No se comprende en esta medida los señores diputados de Chiapas por ser provincia de las que componen la Nacion Mexicana". Así, pues, quedaba consumada la separación de Centro América de México y la anexión definitiva a nuestro país de Chiapas.

Así llegamos al 27 de octubre de 1823 en que se habían reunido la mitad más uno de los diputados electos para el Segundo Congreso Constituyente, posteriormente, el jueves 30 del mismo mes, por la mañana, se celebraría la última reunión del Primer Congreso Constituyente, y por la tarde, la primera reunión preparatoria del Segundo.

Nos relata don Carlos María de Bustamante: ${ }^{94}$

Entonces el señor presidente Tagle se puso en pie y con voz enérgica y majestuosa dijo "El primer Soberano Congreso Mexicano ha cerrado sus sesiones hoy 30 de octubre de 1823 ". Inmediatamente quedó disuelta tan ilustre asamblea, pero dejando en todos los circunstantes una impresión profunda, mezcla de pesar y satisfacción, que no es dado a mi pluma expresar.

94 Cfr. Diario..., cit., correspondiente al 30 de octubre de 1823. 


\section{Y continúa:}

Hace un año que se trazó el decreto de su disolución por Iturbide dentro de diez minutos, decreto bárbaro y digno de tal califa; cumplióse sí, se cumplió, pero de los fragmentos y ruinas de tan augusto cuerpo se formó otro edificio; de sus miembros errantes se suscitaron vengadores de sus agravios, que dentro de cinco meses lo reorganizaron y lanzaron de nuestro seno a monstruo tan despiadado...

\section{SEÑOR CHATO, MI QUERIDO SALTILLERO EMBROLLÓN...}

Como señalamos antes, durante la época monárquica se redactaron tres proyectos de constitución: uno, parcial, el de Antonio José Valdés, el atribuido a José Miguel Guridi y Alcocer y el de José María Couto; ${ }^{95}$ tócanos ahora hacer una breve revisión de los proyectos que se formularon ya en la época republicana, previa al inicio de funciones del Segundo Congreso Constituyente.

a)Ya hemos mencionado párrafos atrás como el 16 de mayo de 1823, los diputados Servando Teresa de Mier, ${ }^{96}$ José C. del Valle, José María Jiménez, Juan de Dios Mayorga, Francisco María Lombardo, José Mariano Marín, Lorenzo de Zavala y José María Bocanegra, presentaron un texto que finalmente fue denominado Plan de la constitución política de la nación mexicana. Por la Comisión de Constitución del Congreso, y como el propio Congreso, por Decreto de 21 del mismo mes de mayo, ordenó, además de que se preparara la convocatoria para el segundo Constituyente, se imprimiera y circulara tal Proyecto. ${ }^{97}$

95 Claro, también está el mencionado Proyecto de Reglamento Político de Gobierno del Imperio Mexicano, del cual dimos cuenta páginas atrás, pero como su nombre lo indica no era un proyecto de constitución sino de un texto provisional para dejar de utilizar a la Constitución de Cádiz como norma supletoria.

96 Calvillo (op. cit., p. 453) citando a Alfonso Junco, dice que desde el 14 de mayo Mier había escrito a Ramos Arizpe en estos términos "Señor Chato, mi querido saltillero embrollón... La semana que entra saldrán a la luz las bases liberales de una república representativa federal con un congreso general, su senado...".

97 Cfr. Plan de la Constitución Política de la Nación Mexicana, con el voto particular del Dr. Mier (México, Imprenta Nacional del Supremo Gobierno, 1823) . Citado por Ernesto de la Torre Villar y Jorge Mario García Laguardia, op.cit., p. 103. 
Nos cuenta Jaime E. Rodríguez O.$^{98}$ que por iniciativa del padre Mier, ese grupo de diputados había trabajado en secreto el Proyecto de referencia, el cual fue concluido el día 14 del citado mes, ${ }^{99}$ y que luego el propio Mier logró se formara la Comisión especial que mencionamos antes, la cual estaría integrada, además de los redactores del citado proyecto, por los diputados Javier Bustamante y Valentín Gómez Farías, Comisión que presentaría, dos días después, el mismo borrador con el título de Plan ..., el cual evidentemente no fue discutido por el Congreso ya que el clamor de las provincias era, como lo hemos venido señalando, el que se convocara un nuevo constituyente, lo cual, nos dice el propio Rodríguez, indignó a [fray] Servando, no obstante ello, ya lo dijimos, se ordenó la impresión y distribución del documento.

No se trató propiamente de un proyecto de constitución, ${ }^{100}$ sino como su propio nombre lo indicaba era un Plan de la Constitución Política de la Nación Mexicana, al estilo de los Elementos de don Ignacio López Rayón o los Sentimientos de la Nación suscritos por el generalísimo don José María Morelos y Pavón, ${ }^{101}$ aquí igualmente se trazaron las bases de lo que podría ser nuestra ley fundamental, resultando muy importante por dos razones: fue como la herencia jurídico-política del Primer Congreso Constituyente mexicano al Segundo y porque integró la síntesis de lo que se pensó fueran las primeras decisiones fundamentales del Estado, que estaba emergiendo al concierto mundial de naciones independientes. Tenía dos partes, la primera era una amplia exposición de motivos y la segunda era propiamente la propuesta de los lineamientos de lo que sería la ley suprema.

La decisión republicana ya no tenía vuelta, era irreductible e irrenunciable; el problema era el federalismo, si bien los redactores del Plan eran conscientes de que "quieren república: la quieren federal", no dejaron de apuntar los riesgos que dicho sistema traía consigo, la calificaron de "institución muy peligrosa" "Facilitaría la disolución del mismo estado: debilitaría sus fuerzas: cortaría el vínculo de la unidad: crearía emulaciones y rivalidades: sembraría

98 Op. cit., p. 302.

99 No entendemos por qué Manuel Calvillo dice que fue fechado el 18 de mayo (op. cit., p. 459) ya que páginas adelante, cuando transcribe el texto del mismo, ahí se lee 14 de mayo.

100 Hemos utilizado la reproducción que de dicho Plan hizo Manuel Calvillo, op. cit., pp. 703-724.

101 Cfr. Nuestro modesto trabajo: El pensamiento constitucional en la Independencia, México, Porrúa-UNAM, 2012, pp. 218. 
el germen destructor de la discordia", etcétera. No obstante ello, la Comisión concluyó "respetando la voluntad de los pueblos ha establecido por base, que el gobierno de la nación mexicana será una república representativa y federal"; sin embargo añadía "pero siguiendo la misma guía, le ha dado la organización menos daños a los mismos pueblos", o sea, un federalismo más bien descafeinado.

A continuación, en la misma exposición de motivos, partiendo del principio de que "La comisión no reconoce otro poder y soberanía que la de la nación" hizo una buena exposición de la conveniencia del apotegma de la división de poderes y de ahí pasó a exponer como contemplaban ellos la organización del poder público, empezando por el Legislativo, el cual lo proponían unicameral y daban la explicación de por qué no convenía el bicameral, pues aunque propusieron hubiera un Senado, éste no sería colegislador, sino más bien un organismo de control de constitucionalidad ("No es invención nueva el Senado que se propone. Antes que hubiera Congreso en México, lo propuso uno de los publicistas más acreditados y juiciosos"), ${ }^{102}$ pues afirmaban: "No basta dividir el poder y designar a cada uno sus atribuciones: es necesario ponerlos en la necesidad justa de no exceder de ellas; y éste es el objeto que la comisión ha tenido presente en el Senado que propone". Postulaban la creación de congresos provinciales y que los ejecutivos locales estuviesen a cargo de prefectos. No abordaron en esta exposición de motivos el tema de los ayuntamientos, sino de manera muy tangencial.

La formación ilustrada de los autores del Plan quedó de manifiesto en el capítulo dedicado a la educación, y la importancia que daban a la misma; consideramos importante reproducir el último párrafo de dicho capítulo:

Entonces no se verá la educación uno o dos siglos distante del punto a que se ha elevado la razón; los establecimientos literarios (o sean los centros educativos) no serán como unos puntos fijos que han quedado atrás para medir desde ellos todo lo que han adelantado las ciencias; la instrucción avanzará progresivamente, y generalizándose en diversos grados por todas

102 Recordemos como el diputado constituyente por Guadalajara, Toribio González Moreno, propuso, el 23 de mayo de 1822 , la creación de tres instituciones: el Senado Conservador, el Consejo de Estado y el Tribunal Supremo de Justicia, habiendo cuajado únicamente el Consejo de Estado, que tuvo facultades muy parecidas a las que ahora se pretendían dar al Senado. El ilustre jurista queretano don Juan María Wenceslao Barquera, en su célebre obra Lecciones de política y derecho público para instrucción del pueblo mexicano, facsimilar de la de 1822, México, UNAM, 1991, pp. 197 y ss., ya habla "Del Poder Conservador". 
las clases, será México una sociedad de hombres que conozcan sus intereses, y sepan sostener sus derechos.

En cuanto a la administración de justicia, propusieron que ésta se integrara con las tres instancias a nivel local, y un tribunal supremo cuya misión sería juzgar y velar la conducta de magistrados y jueces, particularmente, a través del recurso de nulidad (casación).

Veamos ahora su propuesta concreta para la estructura constitucional de nuestro país. El Plan, propiamente dicho, se integraba con ocho bases, después de un preámbulo muy de la época. La primera base enunciaba los derechos y deberes de los ciudadanos (entendiendo por tales a los habitantes de la República), hablaba de la soberanía de la nación y a ésta la proclamaba como "una República, representativa y federal".

La segunda base trataba de los organismos representantes de la ciudadanía, entre los que se encontraban: el Congreso Nacional, el Senado, los congresos provinciales y los ayuntamientos; cómo se elegirían a sus integrantes que "no será por ahora directa", de tal forma que habría un diputado al Congreso Nacional por cada 60,000 habitantes, tres senadores por cada provincia; el número de los representantes a los congresos provinciales variaría de acuerdo con la población de cada entidad: 13, 15, 17 o 19. Igual sucedería con los ayuntamientos que iban desde un alcalde, dos regidores y un síndico, hasta cuatro alcaldes, catorce regidores y dos síndicos, dependiendo del número de habitantes.

La tercera base hablaba de las facultades del Congreso Nacional. La cuarta del ejecutivo nacional, que se integraría por tres individuos, nombrados por el Congreso para un período de cuatro años, señalando sus facultades y atribuciones. La quinta base hablaba de los gobiernos provinciales: congresos provinciales y prefectos, señalando las facultades de ambos: La sexta trataba lo relativo a la educación, señalando que todos los particulares podrían formar establecimientos de esta materia, además de los institutos públicos, debiéndose erigir uno nacional y otro en cada una de las provincias, los cuales cultivarían las cuatro clases de ciencias: físicas, exactas, morales y políticas.

La séptima base trataba lo relativo a la administración de justicia y de las garantías jurisdiccionales, ordenaba la preparación de los códigos civil y criminal, disponía de la existencia de jurados tanto para lo civil como para lo criminal y la conciliación en materia civil; en cuanto a la organización judicial, señalaba que existirían, además de alcaldes para la justicia de 
mínima cuantía, jueces de letras, tribunales superiores provinciales (que no los denomina así, sólo habla de los dos magistrados que debería haber en cada provincia, y cómo se debería organizar para las segunda y tercera instancias), así como del Tribunal Supremo de Justicia, integrado por siete magistrados.

El Senado, como señalamos antes, del cual hablaban la octava y última base, no tendría carácter de colegislador, sino de órgano de control constitucional, ${ }^{103}$ tendría facultad de iniciativa, revisaría la constitucionalidad de las leyes, juzgaría a los altos funcionarios del Estado, convocaría a congreso extraordinario y dispondría de la milicia constitucional.

Generalmente se acompaña a este Plan y su exposición de motivos el Voto particular del doctor Mier (fray Servando) en el que, apartándose del criterio de la mayoría en lo tocante a las facultades del Senado, propuso que éste tuviera el carácter de colegislador, como en los Estados Unidos y en Colombia; parece que éste era también el criterio de Javier Bustamante y Lorenzo de Zavala.

Como se habrá podido observar, este documento no fue determinante en la redacción de la Acta Constitutiva de la Federación Mexicana del 31 de enero de 1824, ni de la Constitución Federal de los Estados Unidos Mexicanos del 4 de octubre de 1824. Para nosotros, modestamente opinamos, lo más importante de dicho Plan, fue la consagración del régimen federal en nuestro país, preparado por muy insignes publicistas, la mayoría de los cuales fueron diputados al segundo Congreso Constituyente.

b) En mayo de 1823 se presentó en Monterrey el Plan de las Bases Orgánicas y Fundamentales para el Establecimiento de una República Federada en el Anáhuac Propuesto por el Ciudadano Esteban Austin, aunque Manuel Calvillo, ${ }^{104}$ siguiendo a Nettie Lee Benson, considera que más bien correspondió al mes de junio. En efecto, el virginiano naturalizado mexicano, Stephen F. Austin, considerado como el "padre de Texas", pues condujo a las 300 familias anglosajonas que iniciaron la colonización de lo que después sería el más grande estado de la Unión Americana, presentó este documento a don Miguel Ramos Arizpe como una aportación al proceso político fundamental que en esos momentos vivía nuestro país. Como su

103 Indiscutiblemente inspirado en el Senado Conservador francés, creado por la Constitucion Consular del 22 frimario (13 de diciembre de 1799) redactada por Sieyés.

104 Op. cit., p. 485. 
autor mismo lo confiesa en la exposición de motivos "Las bases generales se han tomado principalmente del Gobierno de Estados Unidos de América".

No es propiamente un proyecto de constitución, sino más bien, la exposición en 25 artículos del sistema constitucional norteamericano, que elaboró Austin después de hablar con el diputado constituyente coahuilense Miguel Ramos Arizpe, quien ya se había decantado por el federalismo, precisamente, repetimos, para ilustrarlo sobre el régimen político de aquel país, de tal suerte que el ejemplar con el que se cuenta viene anotado por el propio "señor Chato, saltillero embrollón", como el padre Mier llamó a su colega en el sacerdocio Ramos Arizpe.

c) Ya hemos visto cómo la antigua provincia de Guadalajara, trasformada desde el 16 de junio de 1823 en estado libre de Jalisco, encabezó en todo el país el movimiento en favor del federalismo, y dentro de los federalistas jaliscienses destaca la figura de Prisciliano Sánchez (aunque era de Nayarit, pero en esa época ese territorio formaba parte de Jalisco), quien fuera electo diputado constituyente en 1822 y participó activamente en las discusiones que se suscitaron en los últimos meses de vida del Primer Constituyente en 1823 sobre este mismo particular. Como resultado de todo ello, fue la propuesta de don Prisciliano fechada el 28 de julio de 1823 con el título de El Pacto Federal de Anáhuac. Posteriormente fue diputado local constituyente en Jalisco, en donde participó en la redacción de la primera Constitución de ese estado, del cual fue su primer gobernador constitucional, cargo en el cual falleció en 1826.

Después de un largo proemio, expone lo que denomina "Indicaciones previas al pacto federal", que no es otra cosa que nueve reglas para gobernar el país en tanto se aprueba la constitución definitiva; posteriormente trata de las bases para ella: propone, igual que Austin, el nombre de Anáhuac para el país, por supuesto lo contempla como una federación. Para darle a una provincia el carácter de estado soberano e independiente pedía una población mínima de 200,000 habitantes, pues en caso de no alcanzar esa cifra, se unirían a un estado vecino en tanto lograban tal cantidad y que fuera declarado estado (especie de lo que después se llamó territorios, aunque no dependientes de la Federación).

Por supuesto se pronunciaba por la división de poderes, encomendando el Legislativo a un Congreso de Diputados; el Ejecutivo podría ser de uno o tres individuos; el Senado, extrañamente, era concebido como parte del Poder Ejecutivo, integrado por uno o dos senadores, y tendría funciones de 
asesoramiento y control constitucional. Hablaba del Poder Judicial, apuntaba sus atribuciones, pero sin señalar su integración. Y en lo que era un poco más explícito era en el régimen interior de los estados. ${ }^{105}$

Evidentemente, la propuesta de Prisciliano Sánchez no prosperó, pero ahí quedó como de los esfuerzos que esos fundadores del Estado Mexicano para constituir nuestra Patria de la mejor manera según su leal saber y entender.

d) Finalmente, mencionaremos el proyecto del doctor Francisco Severo Maldonado. Aunque este sacerdote tuvo un papel destacado durante estos años correspondientes a las segunda y tercera décadas del siglo XIX, particularmente en el Occidente de nuestro país, en ese preciso momento, 1823, no era más que un particular, circunstancia que nos explicará la poca trascendencia que tuvo con posterioridad.

Existe un libro sobre Maldonado, escrito por don Alfonso Noriega Cantú ${ }^{106}$ y otras obras más generales en que abordan someramente su vida y su obra, junto con otros personajes, esfuerzos que no podemos analizar ahora pues ello rebasaría los límites de este trabajo, ahora sólo queremos señalar que a todos ellos los hemos visto con prevención ya que exponen datos no verificados de nuestro autor, como el que don Francisco Severo fue miembro de la Junta Suprema Gubernativa (1821-1822) o diputado al Primer Congreso Constituyente, información que nosotros no hemos visto en ninguna de las fuentes consultadas, por no negarlo contundentemente. Nos confirma este temor el hecho que Manuel Calvillo, en su magnífico libro tantas veces citado en este trabajo, no hable de la vida y obra de Francisco Severo, sólo reproduzca su proyecto.

No nos queda claro el iter que tuvo que recorrer Maldonado para la impresión de la primera edición de su Contrato de Asociación para la República de los Estados Unidos del Anáhuac, que la firmó como "un ciudadano del Estado de Xalisco", y aunque Moisés Guzmán Pérez ${ }^{107}$ hace un esfuerzo para elucidar ello; Noriega Cantú, ${ }^{108}$ nos confunde más al respecto.

105 Curiosamente, con una vena muy regalista, señala que cada estado sería una diócesis, y mientras no se arreglen con Roma esos temas, "habrá en los estados que no tengan obispo, un vicario general, con facultades amplias"; igualmente señala que cada municipio sería una parroquia, "excepto las capitales y pueblos numerosos que se dividirán en más según sea su población”.

106 Francisco Severo Maldonado el precursor, México, UNAM, 1980. 282 p.

107 Cfr. Impresores y editores de la Independencia de México 1808-1821. Diccionario, México, Porrúa-UMSNH, 2010, pp. 149 y 150.

108 Op. cit., pp. 25 y 26. 
Parece que se inició su impresión en la ciudad de México y se terminó en Guadalajara; tampoco nos queda claro si fue en 1822 o 1823. Lo que sí queda más precisado es que hubo una segunda edición en Guadalajara, en 1823, entonces sí suscrita por el doctor Severo Maldonado.

El proyecto de Contrato de Maldonado es un mazacote, que trata de todo y de nada, se nota que don Francisco Severo prácticamente no tenía experiencia constitucional y lo redactó más con buenas intenciones que con sólidos conocimientos jurídico-fundamentales; sabemos, además, que no influyó particularmente en los constituyentes, por lo que no nos entretendremos más con esta propuesta. ${ }^{109}$

Se inicia, según la costumbre de la época, con un proemio, tan lleno de autoelogios que termina por decir: "esta constitución es como el sol, de cuya luz y benéficas influencias no hay ninguno que no participe", como se verá, la humildad no era la virtud dominante del padre Maldonado. Luego, como señalamos antes, a través de 230 artículos desarrolla propiamente su propuesta de ley fundamental, en donde mete las cuestiones más increíbles como el artículo 188 en que señala: "Pasado este tiempo de purgación (o sea, cumplir una sentencia), el reo se ocupará alternativamente en actos de piedad y religión, y en labores de manos...". Concluyendo con unos “Apuntes. Sobre un tratado de confederación general entre todas las Repúblicas Americanas" y cinco anexos en que trata propuestas económicas. Quizá más adelante, con una finalidad meramente academicista, algún culto historiador del derecho podría hacer el ejercicio de análisis e interpretación de estos curiosos textos.

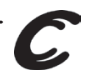

109 Don Carlos María de Bustamante, en su Diario Historico (cit) correspondiente al 28 de mayo de 1823, dice: "Ayer ha salido para Guadalajara el ciego don Francisco Severo Maldonado, autor del Pacto Social y hombre de todas las facciones; acompáñalo el canónigo don Toribio González, diputado de aquella provincia en el Congreso, y marcado con la nota se servilismo; marcha huido pues el Congreso le ha negado repetidas veces la licencia por la causa indicada" (el subrayado es nuestro).

Fecha de recepción: 26 de enero de 2012.

Fecha de dictamen: 17 de abril de 2012. 